\title{
Gertrudis Gómez de Avellaneda oder romantisches Schreiben zwischen Kuba und Spanien
}

Mit Gertrudis Gómez de Avellaneda stoßen wir auf eine große Autorin, um die sich noch immer in eigenartiger, aber charakteristischer Verbohrtheit zwei nationale Literaturgeschichtsschreibungen streiten. Denn ebenso die spanische wie die kubanische Literaturgeschichtsschreibung reklamieren diese Dichterin vehement für sich - und nur für sich! Besonders hübsch und putzig sind in diesem Zusammenhang die Ausführungen von keinem Geringeren als Don Marcelino Menéndez y Pelayo, der die Avellaneda aufgrund ihrer Bildung und Ausbildung für eine Spanierin hält, könne diese hochgebildete Dichterin - so der spanische Literaturpapst - doch niemals die kubanische Literatur vertreten. Und Lorenzo Cruz-Fuentes hat in seiner 1907 erschienenen Ausgabe der von ihm aufgespürten Autobiografía der Autorin und ihrer Briefe an Cepeda betont, wie lächerlich und absurd der Standpunkt des damaligen kubanischen Vizepräsidenten Zayas sei. Denn der kubanische Politiker und Kritiker habe davon gesprochen, dass Tula, wie man die in Kuba geborene Dichterin auch nannte, die spanische Literatur für die kubanische Literatur von kubanischer Seite her erobert habe, dass sie also als Kubanerin letztlich die spanische Literatur der ihren, der kubanischen unterworfen und einverleibt habe.

All dies mag heute ein wenig wie in die Jahre gekommene Folklore erscheinen. Tatsache aber ist, dass sich Gertrudis Gómez de Avellaneda bis heute entweder als Kubanerin oder als Spanierin durch die verschiedenen Literaturgeschichten treibt und mit ihrem Namen entweder für die iberische oder die karibische Literaturtradition einsteht. Dies ist durchaus auf Grund der differierenden und differenzierenden Entwicklung der Disziplinen und der nationalen Geschichtsschreibungen verständlich, verweist aber auf die Absurdität derartiger Anschauungen und letztlich auch auf die Borniertheit oder zumindest doch Relativiertheit und Begrenztheit einer derartigen Literaturgeschichtsschreibung. Keine Angst, wir werden uns einer derart exkludierenden und essentialisierenden Literaturwissenschaft nicht verschreiben!

Zum Thema Bildung und Erziehung hatte die gute Tula - wie wir sie bisweilen nennen dürfen - das Nötige schon zu ihrer Zeit gesagt, schrieb sie doch im Jahre 1839 in ihrer Autobiographie, auf die wir gleich zurückkommen werden, einige recht interessante Zeilen $\mathrm{zu}$ einem Vergleich zwischen ihrer Heimatinsel und Spanien. Sie verglich darin die unterschiedliche Erziehung von Mädchen in Kuba und in Spanien, wobei sie als echte Kubanerin Galizien heranzog, ist doch auf Grund der zahlreichen Einwanderer aus diesem Teil des Landes ein Spanier für kubanische Seelen doch stets ein „Gallego“: 
Die Erziehung, die man in Kuba den jungen Fräuleins gibt, weicht so sehr von der ab, welche sie in Galicien erhalten, dass eine Frau aus meinem Land selbst von mittlerer Klasse sich zu degradieren glaubte, wenn sie das ausübte, was in Galizien selbst die reichsten als eine Verpflichtung ihres Geschlechtes ansehen. Die weiblichen Verwandten meines Stiefvaters etwa sagten, dass ich zu nichts gut sei, da ich weder bügeln noch kochen noch Socken stopfen konnte, weil ich die Gläser nicht abwusch noch die Betten machte oder mein Zimmer ausfegte. Ihnen zufolge brauchte ich zwanzig Dienstmädchen und hätte dabei die Allüren einer Prinzessin. Auch machten sie sich über meine Neigung zum Studium lustig und nannten mich Die Frau Doktorin. [...]

Nachdem ich mit meinen zarten Verpflichtungen gebrochen hatte und mich wieder als frei, wenn auch nicht als glücklicher ansah, war ich überzeugt davon, mich niemals verheiraten zu müssen und dass die Liebe mehr Schmerzen als Lust hervorrufe; und so nahm ich mir vor, nach einem System zu leben, das ich schon seit längerer Zeit im Kopf hatte. Ich wollte, dass die Eitelkeit an die Stelle des Gefühls träte, und es schien mir besser, im Allgemeinen zu gefallen, als von einem Einzigen geliebt zu werden: Und dies umso mehr, als dieser Eine niemals meine Vorstellungen gänzlich erfüllen könnte. Ich hatte die Hoffnung verloren, einen Mann nach meinem Herzen zu finden. ${ }^{1}$

Diese Passage ist nicht uninteressant, denn sie zeigt, wie sehr sich in Sachen Frauenbildung und weiblicher Erziehung in Kuba längst eine andere gesellschaftliche und kulturelle Entwicklung angebahnt und verwirklicht hatte, die mit der in Spanien, hier in Galizien üblichen nur noch entfernt verwandt war. Das weibliche Selbstverständnis der jungen Avellaneda ist deutlich kubanisch geprägt und geht innerhalb dieser Area der Karibik unverkennbar von einer geringeren geschlechterspezifischen Determination aus als in Galizien. Denn warum sollte nicht auch eine Frau sich dem Studium widmen, sich für eine Tätigkeit in den Schönen Künsten öffnen und das Sockenstopfen und Bettenmachen dafür hübsch bleiben lassen?

Es ist keine Frage: Zweifellos hat diese emanzipatorische Bewegung in erster Linie mit der Sklavenhaltergesellschaft in Kuba zu tun, die innerhalb der Autobiografia aus dem Jahr 1839 nur ein einziges Mal erscheint! Denn die Sklaverei - das heißt die Beschäftigung von Sklaven nicht allein auf den Zuckerrohrplantagen, sondern auch als Haussklaven im privaten Bereich - stellte gleichsam den verschwiegenen Hintergrund für die Veränderung der Frauenrollen dar. Sie war mitverantwortlich für die Tatsache, dass selbst die kubanische Mittelklasse - von der hier die Rede ist - ihre Töchter fernab hausfraulicher Notwendigkeiten erziehen konnte, welche von den Sklaven beziehungsweise Sklavinnen stillschweigend übernommen und getragen werden mussten. Dies ist ein für diese Area der Karibik sicherlich wichtiger Punkt, der sich auch in viele andere Lebensbereiche der Bevölkerung hinein auswirkte.

1 Gómez de Avellaneda, Gertrudis: Autobiografía y epistolarios de amor. Newark US: Juan de la Cuesta 1999,S. 73. 
Einen weiteren zentralen Aspekt aber bildet zweifellos die Tatsache, dass Gertrudis Gómez de Avellaneda in ihrer weiblichen Autobiographie zugleich auch das Studium, die Anhäufung von Wissen für sich in Anspruch nimmt, was ihr die Verhohnepiepelung durch ihre galizischen, also spanischen Geschlechtsgenossinnen einbringt. Denn diese Anhäufung von Wissen, das zugleich immer auch Macht ist, war in erster Linie den männlichen Nachkommen beziehungsweise Männern vorbehalten. Der Anspruch auf eine Befreiung als Frau aber konnte nicht unabhängig von Bildung und Ausbildung gedacht werden; und hier liegt sicherlich gerade das emanzipatorische Hauptmoment der Überlegungen der Avellaneda mit Blick auf eine Gleichberechtigung der Frauen.

Vor diesem gesellschaftlichen Hintergrund wird deutlich, warum die kubanische Autorin in der Folge fast übergangslos die zentrale Institution der Ehe in Frage stellte, bringe sie doch für die Frau mehr Schmerzen und Verluste mit sich als Lüste und Gewinne. Es ist daher nicht überraschend, dass sie im argumentativen Zusammenhang ihrer Autobiografía die Verlobung mit einem Manne auflöst, um sich endlich wieder frei fühlen. Nun kann sie ein neues ,System leben, das die Vanitas, die Eitelkeit an die Stelle der Liebe rückt und ihr weibliches Selbstbewusstsein wie auch ihr Selbstwertgefühl als Frau erhöht, ohne sich doch in Abhängigkeit von Männern zu begeben. Die Männer, so das ,System“ der Gertrudis Gómez de Avellaneda, sollen sie bewundern, aber ihr nicht zu nahe kommen und sie in Abhängigkeiten verwickeln.

Wer die Geschlechterbeziehungen zwischen Mann und Frau hinterfragt, rüttelt damit selbstverständlich an den Eckpfeilern der bürgerlich-ecclesialen Ständegesellschaft Spaniens, den Grundpfeiler gleichsam der patriarchalen und phallogozentrischen Gesellschaft überhaupt: Gertrudis Gómez de Avellaneda kündigt damit jegliche Unterordnung unter einen Mann auf. Eine Tatsache, die sie - wie sie sehr wohl weiß - nicht glücklicher machen werde, aber selbstbestimmter und selbstbewusster.

Dies ist für ihr Leben insgesamt sicherlich eine zutreffende Einschätzung: Die am 24. März 1814 im Camagüey auf Kuba geborene und am 1. Februar 1873 in der spanischen Hauptstadt verstorbene Dichterin ging sicherlich einen anspruchsvollen, ja schweren Weg als Frau und Schriftstellerin, auch wenn dieser von großen literarischen Erfolgen und ungeteilter Bewunderung gesäumt war. Die Tochter eines Kommandanten der spanischen Flotte wuchs in begüterten Umständen im Osten ihrer kubanischen Heimatinsel glücklich auf. Früh schon zeigte sich ihr Talent für Theater und fingierte Szenerien, ihr Geschick als Autorin erster Gedichte und ihr rebellischer Geist, der sie ihr Leben lang niemals verließ: weder in ihrem Geburtsland Kuba noch in ihrer Wahlheimat Madrid, wo sie sich ab 1840 dauerhaft niederließ. 


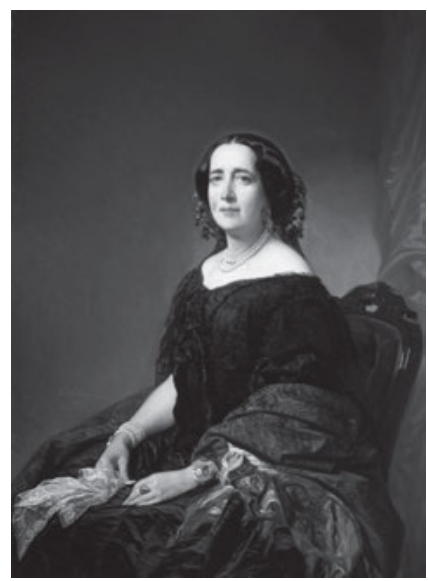

Abb. 36: Gertrudis Gómez de Avellaneda (Santa María de Puerto Príncipe auf Kuba, 1814 - Madrid, 1873).

An Liebeleien wie stürmischen Liebesbeziehungen fehlte es im Leben der schönen Kubanerin keineswegs. Ihre Autobiografía präsentiert uns eine Vielzahl von Beispielen ihrer zumeist unglücklich verlaufenen Liebeserlebnisse und Liebesaffären, welche sie freilich nie aus der Perspektive einer Heirat denken konnte. Allen romantischen Liebesbeziehungen, aber auch zwangsweisen Verheiratungen entzog sich die unabhängige Kubanerin rechtzeitig. Ihre Autobiographie ist im Übrigen primär an einen einzigen Adressaten gerichtet: Don Ignacio de Cepeda, ihren damaligen Liebhaber, dem sie ihre Herkunft, ihr Denken und ihren Lebensstil zu erklären suchte, wobei sie ihn zu Beginn und am Ende bittet, dieses Schriftstück sogleich wieder zu verbrennen. Ihr Adressat hat dies glücklicherweise nicht getan, und so besitzen wir ein wunderbares autobiographisches Zeugnis von dieser großen Dichterin der Romantik.

Gerade der Blickwinkel der Selbstreflexion für den geliebten Mann zeigt eine Frau, die ihr Leben zwar nicht ohne Männer, wohl aber ohne den einen und einzigen Mann - obwohl dieser als Traumvorstellung noch nicht endgültig verabschiedet wurde - zu leben gewillt ist. Ihre Autobiographie ist daher ein unschätzbares Zeugnis vor dem Hintergrund der Tatsache, dass es sich im Grunde um einen Geschlechterdialog im romantischen Zeitalter handelt. Dieser ist eine Art Selbstverständigungstext von ungeheurer Bedeutung, der uns einen Einblick in die Diskurse gerade auch zwischen den beiden Geschlechtern zu jenem Zeitpunkt, auf der Höhe der Romantik in Spanien gibt. Gertrudis Gómez de Avellaneda ließe sich an dieser Stelle zweifellos in eine Abfolge großer Frauengestalten stellen, die von Germaine de Staël bis Juana Borrero das 19. Jahrhundert nicht nur in der Romania prägten. Wir werden uns in unserer Vorlesung mit diesen großen Repräsentantinnen eines 19. Jahrhunderts zwischen zwei Welten ausführlich auseinandersetzen. 
Lassen Sie uns an dieser Stelle aber noch einmal auf einige biographische (und danach erst autobiographische) Elemente im Leben der kubanischen und spanischen Dichterin kommen, die an beiden Literaturfeldern partizipierte: Als María Gertrudis de los Dolores in Puerto Príncipe, in der heutigen Provinz Camagüey, geboren wurde, war ihr spanischer Vater bereits seit 1809 als „Comandante de Marina“ für Zentralkuba auf der Insel. Vergessen wir nicht, dass für Spanien die Insel Kuba lange Zeit die „siempre fiel Isla de Cuba“, die stets treue Insel Kuba war, da sich die Antillen nicht dem Unabhängigkeitskampf auf dem Festland anschlossen! Denn hier hatten die Kreolen andere Ziele und versuchten, an den Eigentumsverhältnissen wie an der Sklaverei möglichst wenig zu ändern. Tula ist, mit einem Wort, als Tochter eines Spaniers auf Kuba eine kubanische Kreolin.

Ihre Mutter ist „cubana de familia patricia“, stammt also ihrerseits aus einer wohlhabenden kreolischen Patrizierfamilie. Sie bringt insgesamt fünf Kinder zur Welt, von denen zweie überleben: Manuel und Gertrudis, die bald schon Tula genannt wird. Als mit neun Jahren ihr Vater stirbt, heiratet ihre Mutter bereits zehn Monate später - also noch vor dem Ende der offiziellen Trauerzeit - Don Gaspar Escalada, seinerseits „Teniente Coronel“ in Puerto Príncipe, dem heutigen Camagüey. In ihrer Autobiographie spricht sie von ihrer ungeheuren Lust, mit anderen Mädchen zusammen Tragödien zu lesen und aufzuführen. Früh schreibt sie auch schon Gedichte und Romane über Giganten und Vampire, doch sei ihre wahre Leidenschaft das Theater gewesen. Französisch habe sie nur gelernt, um welch eine Lust! - Corneille und Racine deklamieren zu können. Doch auf Grund ihrer damit verbundenen großen Erregung wird ihr verboten, Theaterstücke $z u$ lesen. Und da sie sie nicht mehr lesen durfte, schrieb sie eben welche, wie sie später kommentierte. Bisweilen sei sie danach fiebrig ins Bett gefallen: Ihre Imagination ist ganz von Fiktionen erfüllt. Kurz vor ihrer geplanten Hochzeit bricht sie die Verbindung mit dem jungen Kubaner Loynaz zum Entsetzen ihrer Familie ab. Sie wird in der Familie zur „niña difícil“, zum schwierigen Mädchen. Sie selbst aber fühlt sich als eine „romántica salvaje a la moda“, als wilde Romantikerin im Trend - und wird dies ihr Leben lang bleiben; denn längst war auch auf Kuba die Romantik angesagt.

Dann aber beginnt das Leben der Tula zwischen beiden Welten: Am 9. April 1836 schifft sich die ganze Familie in Santiago de Kuba nach Europa ein. Mit vielen schriftstellerischen Illusionen bricht die junge Avellaneda nach Spanien auf. Sie schreibt bei der Einschiffung das berühmte Sonett Al partir mit der oft zitierten und zelebrierten Anrufung Kubas. Ich möchte Ihnen in aller Kürze dieses Sonett vorstellen, wobei ich in meiner Übersetzung wieder nahe am Original bleibe und dennoch versuche, für Sie das Versschema wiederzugeben: 
Perle des Meers! Stern vom Okzident!

Schönstes Kuba! Deines Himmels Feuer bedeckt die Nacht mit ihrem dunklen Schleier, so wie der Schmerz mein traurig Antlitz grämt.

Aufbruch ist's! ... Der Matrosen eifrig Händ, vom Boden mich zu reißen, der mir teuer, die Segel hissen, und zur Feier die Brise bläst mich fort, wo's tropisch brennt.

Adieu, geliebtes Vaterland! Du Eden! Wohin mich auch mein Schicksal treibt, Dein süßer Name wird mein Ohr beleben!

Adieu! ... Wind an den Segeln reibt! Die Anker hoch ... Das schiff will schweben, will Wellen schneiden, schwimmen, wie es leibt. ${ }^{2}$

¡Perla del mar! ¡Estrella de Occidente! ¡Hermosa Cuba! Tu brillante cielo la noche cubre con su opaco velo como cubre el dolor mi triste frente.

¡Voy a partir! ... La chusma diligente, para arrancarme del nativo suelo las velas iza y, pronta a su desvelo, la brisa acude de tu zona ardiente.

¡Adiós, patria feliz, edén querido! ¡Doquier que el hado en su furor me impela, tu dulce nombre halagará mi oído!

¡Adiós! ... Ya cruje la turgente vela ... El ancla se alza ... El buque, estremecido, las olas corta y silencioso vuela.

2 Gómez de Avellaneda, Gertrudis: Poesías de la señorita da. Gertrudis Gómez de Avellaneda. Madrid: Establecimiento Tipográfico 1841, „Al partir“, S. 7. 


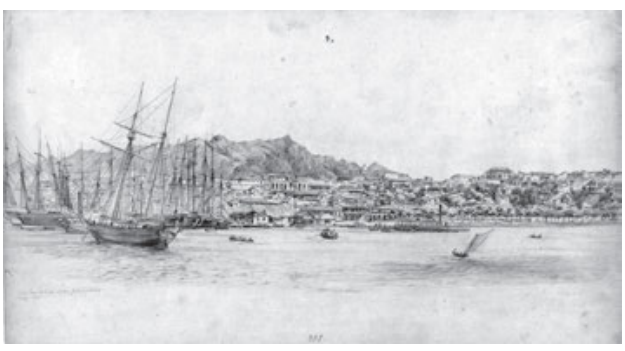

Abb. 37: „Santiago de Cuba vom Hafen aus, März 1853“, Bleistiftzeichnung von Adolf Hoeffler.

Al partir ist ein Abschiedssonett an ihre geliebte Heimatinsel, in welchem kein Topos aus der Tropenwelt fehlen darf und auch das Zeichen Kubas, der einsame Stern, gegenwärtig ist und die Szenerie mit seinem transzendenten Licht beglückt. Das Sonett der Avellaneda ist nahe an seiner klassischen Form und weist bezüglich des Versschemas keinerlei Besonderheiten oder Auffälligkeiten auf. Die heimatlichen Tropen erscheinen als ein Eden, als weites Paradies, in welchem die oft als „Perle der Karibik“ apostrophierte Insel wie ein Ort der Glückseligkeit, ein „locus amoenus“, lockt. Alles in diesem Aufbruch ist dem Hier und dem Vaterland dieser Kreolin verpflichtet. Und dennoch ist der Aufbruch ins Ungewisse eine Verlockung, welcher bei allem Abschiedsschmerz das lyrische Ich und gewiss auch die junge Kubanerin letztlich freudig entgegengeht.

Auf dem Schiff rezitiert sie Gedichte von José María Heredia, dem kubanischen ,Nationaldichter - denn Kuba war wie Deutschland lange vor der politischen und staatlichen Nationenbildung eine Kulturnation, die noch jahrzehntelang bei allem Wunsch der kreolischen Oligarchie nach größerer Autonomie zu Spanien hielt. Nach der Atlantiküberquerung trifft das Schiff in Bordeaux ein, von wo aus man nach einer Woche Aufenthalt gen La Coruña weitersegelt. Gertrudis hält es in Galizien aber nicht lange aus, flieht von dort und bricht erneut eine geplante Verlobung mit einem jungen Spanier ab. Danach folgt eine Reise nach Portugal, wo die Familie ihres Vaters lebt. Zeitweise lässt sie sich in Sevilla nieder, wo sie von einem Teil des väterlichen Erbes lebt. Die junge Dichterin widmet sich ausschließlich der Literatur und dem gesellschaftlichen Leben. Als verführerische Frau erregt sie zahlreiche Liebesgefühle; und einer ihrer Verehrer fällt fast einem Selbstmord zum Opfer. Zugleich verliebt sie sich vehement in Ignacio Cepeda, der sie jedoch wegen ihrer Feurigkeit, ihrer „fogosidad“ fürchtet. Die Briefe an den jungen Mann zählen zu ihren schönsten literarischen Werken und zeugen von der romantischen Liebessehnsucht der Kubanerin.

Ihr schriftstellerisches Oeuvre wächst. Ab 1839 arbeitet sie an der literarischen Zeitschrift La Aureola mit und veröffentlicht zahlreiche Gedichte unter ihrem Pseudonym „La Peregrina“, die Pilgerin. Zugleich übt sie ihr Schreiben durch intensive Lektüren von Walter Scott, Lord Byron, George Sand, Madame de 
Staël, Chateaubriand, Victor Hugo, Alphonse de Lamartine, dem Duque de Rivas sowie José Zorrilla: Sie liest sich begeistert quer durch die europäische Romantik. Im Juni 1840 wird in Sevilla ihr Drama Leoncia über die Problematik einer verführten Frau uraufgeführt, ein ihrem Schreiben wie ihrem Leben innig verbundenes Thema. Doch im Sommer 1840 übersiedelt sie zusammen mit ihrem Bruder nach Madrid, wo sie von nun an leben wird.

Es sind die vielleicht entscheidenden Jahre ihres Lebens, denn sie erklärt nun ihrer Familie offen, dass niemand sie mehr von ihrem Schicksal als Dichterin und Schriftstellerin abbringen könne: die Tula hat sich nun definitiv der Literatur verschrieben und konzentriert sich ganz auf ihre schriftstellerische Arbeit. Ihr Schreibprojekt ist damit zu ihrem Lebensprojekt geworden, sie geht ihren Weg als unabhängige Frau in der spanischen Gesellschaft. Rasch triumphiert sie in den literarischen Milieus von Madrid, wo man sie wegen ihrer Dichtkunst, aber auch ihrer Schönheit feiert; beides weiß sie geschickt für ihre Ziele einzusetzen. Schon bald ist sie aus der literarischen Szene Madrids, aber auch aus der spanischen Literatur der Romantik nicht mehr wegzudenken. In ununterbrochener Folge veröffentlicht sie nun Gedichte und Romane, Erzählungen und Theaterstücke: Es ist die literarisch produktivste Zeit der jungen Kreolin.

Doch so erfolgreich sie auf der literarischen Bühne ist, so verzweiflungsvoll verlaufen ihr privates Glück und ihr fortdauerndes, an unglücklichen Affären reiches Liebesleben. Bisweilen vermischen sich ihre literarischen Erfolge mit ihren Leidenschaften, denn nicht selten verlieben sich spanische Schriftsteller wie Juan Valera in die Kubanerin. Mit dem Dichter Gabriel García Tasara - ein Name, den Sie sich nicht merken müssen - verbindet sie eine von Liebe und Leidenschaft, aber auch von Eifersucht und Angst geprägte Beziehung, die bald schon zum Albtraum gerät; von ihm bekommt sie 1847 ein Kind, das schon wenige Monate später stirbt. Es ist eine der dunkelsten Momente im Leben der Kubanerin, da der Dichter, der sie wohl nur zum Zwecke seiner eigenen Größe verführte, sie schon bald verlässt. Immer wieder wird sie gerade auch in ihren Gedichten auf diese tragische Episode als entehrte Frau und unglückliche Mutter zurückkommen; ein Geschehen, das sie im Madrid der Mitte des 19. Jahrhunderts gesellschaftlich desavouiert. Doch ihr Ruhm als Dichterin bleibt intakt und von den Geschehnissen unberührt: Sie erhält zahlreiche literarische Auszeichnungen. $\mathrm{Zu}$ ihrem Trost vermag sie es auch, ihre Korrespondenz mit Cepeda aufrecht zu erhalten und ihn als Freund ihres Herzens zu bewahren.

Gertrudis Gómez de Avellaneda wird im privaten Bereich von den meisten ihrer Freunde verlassen. Doch im Jahre 1846 bittet der Cortes-Abgeordnete Sabater um die Hand der kubanischen Dichterin. Obwohl zuvor stets einer Heirat gegenüber abgeneigt, nimmt sie diese Geste bewegt zur Kenntnis und willigt gerne in die Vermählung ein. Es ist nicht die große Liebe ihres Lebens, doch sie weiß den 
Antrag zu schätzen, ist sie doch fortan wieder als Frau gesellschaftlich geschützt. Allerdings stirbt der junge, aber kranke Sabater bereits ein halbes Jahr nach der Hochzeit. Es sind ergreifende Momente, die nicht zuletzt auch in der Lyrik der Dichterin ihren Ausdruck finden und ihre religiöse Dichtkunst wesentlich befeuern.

Die einst so rebellische Frau, die sich gegen jegliche Hochzeit sträubte, wird 1855 zum zweiten Mal eine Ehe eingehen, diesmal mit einem „gentilhombre de cámara“, Don Domingo Verdugo. Die Ausnahmestellung der Dichterin in der literarischen Szene Madrids und Spaniens ist ungebrochen: Sie ist die Vertreterin einer romantisch inspirierten Dichtkunst und gleichsam das Gesicht der spanischen Romantik. Ihre Erfolge auf den Bühnen der spanischen Hauptstadt halten an, ihre Dramen - die große Passion ihrer Kindheit - bleiben erfolgreich. Doch ihr Mann wird in einer Auseinandersetzung um eines ihrer Stücke schwer verletzt. Das Paar beschließt 1859, zur Rekonvaleszenz des Gatten die Insel Kuba aufzusuchen, um günstigere klimatische Bedingungen für eine rasche Gesundung zu nutzen. Und so ist die Avellaneda wieder zurück!

Für die kubanische Dichterin ist es die Reise ihrer Apotheose: Die Begeisterung ihrer Landsleute für die aus dem „Oriente“ Kubas stammende Poetin ist ohnegleichen. Am 27. Januar 1860 wird die Avellaneda in Havanna feierlich und nach allen Regeln der Kunst zur Dichterin gekrönt. So ist sie nicht allein das Gesicht der spanischen Romantik, sondern auch der kubanischen Dichtkunst. Doch Gertrudis Gómez de Avellaneda bleibt insgesamt nur drei Jahre auf der Insel, denn im Oktober schon stirbt ihr zweiter Ehemann. Zurück in Spanien kümmert sie sich bis zu ihrem Tod um die Edition ihrer Obras Completas, ihrer Werkausgabe, mit der sie in die spanische wie in die kubanische Literaturgeschichte eingeht und ihre Position zwischen den Welten befestigt.

Nun, dies war ein fürwahr bewegtes und bewegendes Leben, das so ganz den Klischeevorstellungen von einer romantischen Dichterin entspricht! Ich möchte an dieser Stelle gerne noch einmal kurz auf die Autobiographie der damals noch jungen Lyrikerin und Dramaturgin zurückkommen, welche den Zenit ihrer Berühmtheit und Verehrung noch nicht überschritten hatte. Denn in diesem weiblichen Selbstverständigungstext findet sich eine Vielzahl von Verbindungselementen, die uns zu verstehen geben, dass Romantik eine ganz spezifische Form soziokultureller Verbindung von Literatur und Leben ist und keineswegs nur eine Bewegung in der Literatur meint. Romantik impliziert vielmehr auch einen ganz bestimmten Habitus, Denk- und Lebensstil. Wir haben es mit einem spezifischen Wissen vom Leben zu tun, das sich immer wieder rebellisch gegen die dem Leben auferlegten Normen auflehnt und zugleich ein Lebensmodell entwirft, das von einem dankbaren Publikum angeeignet werden kann. Es geht nicht allein darum, bestimmte Situationen des Lebens auszuleben, sondern sie für ein Publikum vor- 
zuleben und zugleich dieses eigene Leben in ein selbständiges Kunstwerk umzudeuten. Romantik impliziert folglich die Verwandlung des eigenen Lebens in ein Werk der Kunst und dessen Modellierung.

Im Folgenden wollen wir einen ganz entscheidenden Moment innerhalb der kulturellen Sozialisation der Avellaneda gemäß ihrer Autobiographie beleuchten: jene Form der Vergesellschaftung von Literatur und jenes Zusammenspiel von Individualität, Melancholie und Einsamkeit einerseits, von Kollektivität, literarischer Erfahrung und Repräsentation andererseits, ohne das die gute Tula einfach nicht zu denken war. Wie beschreibt sie selbst diesen Prozess?

Dennoch war ich niemals fröhlich und leichtsinnig, wie es Kinder gewöhnlich sind. Schon seit meinen ersten Jahren zeigte ich eine Neigung zum Studium und eine Tendenz zur Melancholie. Ich stieß bei den Mädchen meines Alters nicht auf große Sympathien; nur drei meiner Nachbarinnen, die Töchter eines Emigranten aus Santo Domingo, verdienten meine Freundschaft. Es waren drei hübsche Geschöpfe mit einem sehr deutlichen natürlichen Talent. [...] Die Camonas (denn dies war ihr Familienname) fanden leicht an meinem Geschmack Gefallen und teilten ihn. Unsere Spiele bestanden darin, Komödien aufzuführen, Erzählungen auszudenken, wobei wir uns darum stritten, wer sie am hübschesten verfasste, Schätze zu erraten und Wettbewerbe im Zeichnen von Blumen und Vögeln zu veranstalten. Niemals mischten wir uns in die lauten Spiele der anderen Mädchen ein, mit denen wir uns trafen.

Später wurde die Lektüre von Romanen, Gedichten und Theaterstücken zu unserer vorherrschenden Leidenschaft. Mama schimpfte bisweilen mit uns, dass wir doch schon so groß seien und noch immer unser Herausputzen vernachlässigten und wie die Wilden vor der Gesellschaft flöhen, weil es unsere größte Lust war, im Zimmer mit den Büchern eingesperrt $\mathrm{zu}$ sein, unsere Lieblingsromane zu lesen und das Unglück jener imaginierten Helden zu beweinen, die wir so sehr liebten.

Auf diese Weise wurde ich dreizehn Jahre alt. Ach ihr glücklichen Tage, ihr kehrt nicht wieder! ...

In dieser aufschlussreichen und hintergründigen Passage werden zwei Formen der Selbstinszenierung - und zwar einer romantischen Selbstinszenierung - auf paradoxe Weise miteinander verschränkt. Auf der einen Seite steht die geborene Melancholikerin, die schon zu Beginn ihres Lebens von der „maladie du siècle“ erfasst ist. Auf der anderen Seite haben wir es mit einer rückblickenden Idyllisierung der eigenen Kindheit zu tun, welche in nuce bereits alle Elemente dafür enthält, dass aus dem kindlichen Ich die große Künstlerin werden musste. In diesem vieldeutigen Bild der Kindheit, das mit den Töchtern eines Emigranten aus Santo Domingo auch den historischen Hintergrund der Haitianischen Revo-

3 Gómez de Avellaneda, Gertrudis: Autobiografía y epistolarios de amor. Newark US: Juan de la Cuesta 1999, S. $52 \mathrm{f}$. 
lution einspielt und mit den ,Wilden“ auch Tulas eigene Rede von den „salvajes románticos“ einblendet, ist der kleinste gemeinsame Nenner die schwere Süße der Melancholie, welche den Schlusspunkt dieser Szenerie bildet.

In ihren Formulierungen zeigt sich sehr anschaulich, wie das Element der Einsamkeit und einer melancholischen Gesellschaftsflucht die künstlerische Produktivität und Kreativität begünstigt: Im Grunde war die große Dichterin schon immer so gewesen. An anderer Stelle hebt die Avellaneda das Element der „sensibilidad“ und der Empfindsamkeit gerade in künstlerischen Dingen hervor, zugleich aber auch den Begriff des „tedio“, der im Grunde für den französischen Begriff des „ennui“ oder den deutschen der Melancholie und der Langeweile eintritt. Das junge Mädchen hat schon genug von der Gesellschaft, bevor sie diese überhaupt wahrgenommen hat und kennt; sie bevölkert ihre Imagination nicht mit realen Gestalten, die in ihr Leben getreten wären, sondern mit imaginären und erfundenen Fiktionen, welche genauso lebendig vor ihr stehen, wie es die Figuren der Wirklichkeit täten, wären diese auch nur andeutungsweise so interessant. Das Schimpfen der Mutter ist für sie eher noch eine Bestärkung, nicht auf äußeren Putz und Zierrat zu achten, sondern sich ganz auf eine innere Welt mit ihren Leidenschaften und Emotionen zu konzentrieren.

Gertrudis Gómez de Avellanedas Autobiografía versammelt auf wenigen Dutzend Seiten im Grunde alle Verfahrensmuster und Text- wie Lebenselemente, von denen ausgehend sich ein romantischer Lebensentwurf kreativ entfalten kann. Wir beginnen zu erahnen, welche Lektüren, Romane und Gestalten ihre noch kindliche Imagination anregten und aus ihr jene Romantikerin werden ließen, welche die damalige Welt mit ihren Imaginationen erfreute. Es waren die frühen Romantikerinnen und Romantiker, die wie Bernardin de Saint-Pierre, Germaine de Staël oder Chateaubriand jene intertextuellen Spuren legten, die zum eigenen literarischen Werk der kubanischen Dichterin führten.

Die kleine Tula entfaltete ihre kreativen Möglichkeiten und Potenziale just in jenem Bereich, der am Ende des kubanischen 19. Jahrhunderts noch ein letztes Mal in Gestalt Juana Borreros in unvergleichlicher Weise aufscheinen sollte. Bei letzterer handelt es sich um eine Frauenfigur, die ebenfalls durch ihre meisterhaften Zeichnungen ab dem Alter von gerade einmal fünf Jahren sowie ihre frühen Dichtungen die Menschen begeisterte und ihre Sozialisation in einer Gruppe gleichaltriger Mädchen - in diesem Falle ihrer Schwestern - erfuhr. Kann es da ein Zufall sein, dass es sich bei Juana Borrero wohl um die Urgroßnichte von Gertrudis Gómez de Avellaneda handelte? Auch bei ihr finden sich jener Absolutheitsanspruch und jene melancholische Selbstbesessenheit, deren emanzipatorischen Ausfluss wir bei der Avellaneda im Grunde schon ein für alle Mal vorgeprägt sehen. So eröffnet sich ein großer Zyklus emanzipatorischer Frauengestalten und Schriftstellerinnen, der auf Kuba von Gertrudis Gómez de Avellaneda ausgeht und mit Juana Borrero 
ein vorläufiges Ende findet. Am Anfang dieses weiten Bogens im 19. Jahrhundert müssen wir freilich mit Germaine de Staël eine weitere Schriftstellerin platzieren, ohne welche diese Reise unvollständig wäre. Wir werden uns daher mit dieser großen europäischen Autorin im nachfolgenden Kapitel beschäftigen.

Die Auseinandersetzung mit der Gesellschaft wird (nicht nur) bei Gertrudis Gómez de Avellaneda über die Literatur vermittelt; diese liefert jene Vorstellungen, Figurenkonstellationen und Ideen, die später dann im ,richtigen Leben nachvollzogen und nachgelebt werden können. Das Lebenswissen der Literatur verwandelt sich während der Lektüre in ein Erlebenswissen, das schließlich nacherlebt und in das eigene Leben umgesetzt werden kann. Denn Literatur ist nicht ich wiederhole es gerne - Darstellung von Wirklichkeit, sondern Darstellung gelebter oder lebbarer Wirklichkeiten.

Literarische Texte erfüllen die Imagination der jungen Leserin, der künftigen Autorin mit Leben. Chateaubriand oder der junge Goethe, Victor Hugo oder George Sand werden wie viele andere zu Tulas Helden und Heldinnen: Die literarischen Figuren dieser Autor*innen prägen in einer ganz grundlegenden Weise ihr eigenes Lebensprojekt und ihr Vorhaben, sich als Theaterautorin, Dichterin und Romancière zu verwirklichen. Es mag durchaus sein, dass Marcelino Menéndez y Pelayo an dieser Stelle wirklich Recht hat: Ohne Gertrudis Gómez de Avellaneda wäre die romantische Dichtung Spaniens - aber auch jene Kubas - nicht vollständig. Die große Dichterin der Romantik ergänzt jenes Element eines selbstbewussten weiblichen Lebensentwurfes, der so oft an der Wirklichkeit scheiterte und dem Gustave Flaubert mit seiner Emma Bovary ein klarsichtiges, bisweilen zynisches, stets aber bitteres und zugleich humorvolles Denkmal gesetzt hat. Bei der Betrachtung dieses postromantischen literarischen Frauenportraits der Romantik gefriert einem noch heute das Lachen auf den Lippen!

Beide aber, die kubanische Tula wie die französische Emma, stellen Lebensentwürfe von Frauen dar, die uns zu verstehen geben, dass wir niemals - und in der Romantik noch weniger - Leben und Literatur auseinanderdividieren dürfen. Wir sollten beide aber auch nicht unbesehen miteinander vermischen! Es handelt sich vielmehr bis zu einem gewissen Grad um gelebte Literatur und literarisiertes Leben, in dem die kreative Aneignung von Lebensentwürfen zum eigentlichen Hauptthema des Lebens wie des Lesens wird.

Ich möchte Ihnen gerne an einem letzten Auszug aus der Autobiographie dieser Autorin einen Einblick in das tiefe Verwoben-Sein von Leben und Literatur ermöglichen. Es handelt sich um die Szenerie der Abreise aus Kuba, jener Augenblick also, als Tula ihr berühmtes Sonett Al partir verfasste, mit dem wir uns zuvor beschäftigten. Im folgenden Zitat geht es um die Bearbeitung ihrer autobiographischen Rückschau auf ihre Heimatinsel und damit um jenen Augenblick, als sich ein Leben der Romantik zwischen zwei Welten konkretisiert: 


\begin{abstract}
Am 9. April 1836 schifften wir uns auf einer französischen Fregatte nach Bordeaux ein und gaben traurig und heulend wie Undankbare jenes geliebte Land auf, das wir vielleicht niemals mehr wiedersehen werden.

Entschuldigen Sie; meine Tränen benetzen dieses Papier; aber ich vermag mich nicht ohne innere Rührung an jene denkwürdige Nacht erinnern, in der ich zum letzten Male Kubas Erde sah. Die Schifffahrt war für mich ein Quell von neuen Emotionen. -,Wenn wir über die bläulichen Meere schiffen“, so sagte Lord Byron, „sind unsere Gedanken so frei wie der Ozean.“- Seine sublime und poetische Seele musste es so fühlen: Auch die meinige erlebte es genau so. Schön sind die Nächte in den Tropen, und ich habe sie genossen; aber schöner noch sind die Nächte auf dem Ozean. Es gibt eine unbestimmbare Verzauberung in diesem Wehen der Brise, welche die Segel bläht, die im bleichen Glanz des Mondlichts erzittern, welches die Wasser reflektiert, in jener Unermesslichkeit, die wir über unseren Köpfen und unter unseren Füßen sehen. Es ist, als ob Gott sich besser der erregten Seele inmitten jener beiden Unendlichkeiten enthüllte - Himmel und Meer! - und als ob eine rätselhafte Stimme inmitten des Rauschens des Windes und der Wellen erklänge. Wäre ich Atheistin gewesen, so hätte ich damals damit aufgehört. ${ }^{4}$
\end{abstract}

In dieser sorgsam ausgearbeiteten Passage erscheint die Küste des geliebten Heimatlandes ein letztes Mal und wird entsprechend tränenreich verabschiedet. In der Tat finden sich auf dem Papier des Manuskripts auch heute noch die Rückstände von Tränen, so dass sie die Schreibsituation wie die Rezeptionssituation gleichsam an der Wellung des Papiers erkennen können. Am Ende des 19. Jahrhunderts wird uns mit Juana Borrero wieder eine kubanische Dichterin entgegentreten, welche in ihren Cartas de amor, ihren Liebesbriefen, die vergossenen Tränen wie das vergossene Blut in diese haptische und optische Gestaltung der Schreibunterlage buchstäblich einfließen lässt. Auch auf dieser Ebene ergibt sich jener umfassende Zyklus eines Schreibens im Zeichen der Romantik oder auch in nachromantischer Zeit, welcher die kubanische Literatur zwischen zwei Welten über mehr als sechs Jahrzehnte des 19. Jahrhunderts hinweg zu einer erstaunlichen und zugleich faszinierenden Einheit weiblichen Schreibens formt.

Freilich kommt an dieser Stelle ein weiteres Element hinzu, in dem sich Literatur und Leben verbinden: Es geht um die explizite Bezugnahme auf Lord Byron, die sich in einem Zitat niederschlägt, das gleichsam wie eine Folie wirkt, auf deren Hintergrund die konkrete eigene Lebenserfahrung angesiedelt und nachgelebt wird. Mit Hilfe dieses Zitats wird der Mechanismus des Nacherlebenswissens in den Literaturen der Welt präzise vorgeführt: Denn angeführt wird, was man nachempfunden und nacherlebt hat.

Zugleich zeigt sich natürlich, dass die Romantik keine nationalen oder nationalphilologischen Grenzen kennt, ist doch in dieser Passage die Sprache

4 Gómez de Avellaneda, Gertrudis: Autobiografía, S. 62 f. 
des Herzens und der scheinbaren Unmittelbarkeit der Empfindung auf dieselbe oder doch ähnliche, zeitspezifische Weise vorkodiert und wird sie doch getreu im Spanischen nachvollzogen, ,nachgefühlt‘. Die Unermesslichkeit des Raumes ist sicherlich in einem Zusammenhang zu sehen mit der sozialen Erfahrung der jungen Frau, die bei der Abreise aus Kuba wohl zum ersten Mal aus ihrer gewohnten und räumlich begrenzten Erfahrungswelt heraustritt, um die Weite der Welt kennenzulernen.

An dieser Stelle ergibt sich bereits ein Bezug zu den Frauenreisen der Romantik, zu den Reiseschriftstellerinnen des 19. Jahrhunderts, in denen häufig genug der Gegensatz zwischen der Enge einer geschlechterbedingten Welt zuhause und der Weite der Erfahrungswelt vorgeführt wird. ${ }^{5}$ Dies gibt jener Erfahrung der Weite des Ozeans sicherlich eine zusätzliche Dimension, die gerade auf die spezifisch körperliche Erfahrung - im wörtlichen Sinne des Fahrens - der Weite von Lebensentwürfen abgestellt ist. Dass hierbei eine christliche Isotopie nicht fehlen darf, ist letztlich - wie so oft - keinem anderen als Chateaubriand geschuldet, der in die romantische Erfahrung des Seins das christliche Element aus der Erfahrung des Schönen, als spezifisch ästhetische Erfahrung also, eingespielt und integriert hat. Sein Génie du Christianisme kommt in dieser Schiffsreise von Santiago de Cuba nach Bordeaux und weiter nach Spanien als implizites Zitat zu jenem expliziten Lord Byrons hinzu und vermittelt eine Sicht- und Seins-Weise der Romantik, die sich hier in der Tat zwischen zwei Welten inmitten des Ozeans lokalisiert.

Ich möchte Ihnen gerne an dieser Stelle einen kleinen vergleichenden Ausblick geben auf einen Text und eine Reise, die sich fast im selben Zeitraum ansiedeln und welche die junge Französin Flora Tristan, den engen Kreis ihrer Familie in Frankreich verlassend, aus erbrechtlichen Gründen zu einem anderen Zweig ihrer Familie nach Peru führten. ${ }^{6}$ Beide Frauen überqueren also den Ozean, und beide Frauen greifen auf die Metaphorik der Wallfahrt zurück. Während sich Gertrudis Gómez de Avellaneda des Pseudonyms „La Peregrina“ bei zahlreichen ihrer Gedichte bediente, lautete der von Flora Tristan für ihren Reisebericht gewählte Titel Pérégrinations d'une paria. Wichtig ist in beiden Fällen, dass es sich hierbei um Frauen handelt, die ihren gesellschaftlichen Status als Frauen auf sehr eigenständige Weise reflektieren und als Vorläuferinnen feministischen Emanzipa-

5 Vgl. hierzu Abel, Johanna: Transatlantisches KörperDenken. Reisende Autorinnen in der hispanischen Karibik des 19. Jahrhunderts. Berlin: Verlag Walter Frey - edition tranvía 2015.

6 Vgl. hierzu das Flora Tristan gewidmete Kapitel in Band 1 der Reihe „Aula“ von Ette, Ottmar: ReiseSchreiben. Potsdamer Vorlesungen zur Reiseliteratur. Berlin - Boston: Walter de Gruyter 2020, S. 543-555. 
tionsbestrebens zu betrachten sind, ihr durchaus unterschiedliches Denken aber immer wieder in sehr ähnliche metaphorische Darstellungsweisen übersetzen.

So darf ich Ihnen als Ausblick auf eine spätere Auseinandersetzung mit der mich immer wieder von Neuem faszinierenden Flora Tristan an dieser Stelle bereits den Ausklang ihres Reiseberichts kurz einblenden, um meine Überlegungen auch mit Blick auf die Romantik zwischen zwei Welten anhand dieser Frauenreisen zu belegen. Es handelt sich um die Szene der Abreise jener Französin aus Lima, also um den Abschied von einer problematischen Lateinamerika-Erfahrung, die für Flora Tristan nicht nur erbrechtlich enttäuschend verlief. Am Ende ihres Reiseberichts steht der Beginn der nicht mehr behandelten Rückreise über die USA nach Frankreich:

Ich tat allem Genüge, und am 15. Juli 1834 verließ ich Lima gegen neun Uhr morgens, um mich nach Callao zu begeben. [...] Nach dem Abendessen ließ ich meine Habseligkeiten an Bord der William Rusthon bringen und richtete mich in der Kabine ein, die zuvor Frau Gamarra belegt hatte. Am nächsten Morgen empfing ich noch mehrere Besuche aus Lima; es war der letzte Abschied. Gegen fünf Uhr lichtete man den Anker, alle zogen sich zurück; und ich blieb alleine, völlig alleine, zwischen zwei Unermesslichkeiten, dem Wasser und dem Himmel. ${ }^{7}$

Die Parallelen zwischen beiden Szenen der Abreise sind offenkundig: Denn in beiden findet sich das weibliche Subjekt dem Unermesslichen und Unbegrenzten gleich in doppelter Form gegenüber, als Unermesslichkeit des Meeres und als Grenzenlosigkeit eines Himmels, der bei Flora Tristan freilich nicht mehr Sternbilder zeigt. Denn während es bei Gertrudis Gómez de Avellaneda eine erste Schiffsreise als Aufbruch nach Europa ist, bei der sich die Reisende rasch nach einem schweren Abschied von ihrer Heimatinsel den neuen Erfahrungen des Unermesslichen zuwendet und die Konfrontation des einsamen Ich mit der Natur genießt, kehrt Flora Tristan nach Frankreich zurück. Sie wählt aber ebenso die Einsamkeit weiblicher Subjektivität in der Begegnung mit den Weiten des irdischen wie außerirdischen Raumes. Bei beiden jungen Frauen ist die Erfahrung des zu durchquerenden Raumes in einen romantisch eingefärbten und von literarischen Leseerfahrungen gestützten Habitus eingekleidet und somit in ein Lebensgefühl integriert, welches das einsame Individuum in einen Gegensatz zur umgebenden Schöpfung setzt und ein subjektives Erleben des Weiten sowie einer beständigen Weitung befördert.

Wenden wir uns nun einem narrativen Prosatext von Gertrudis Gómez de Avellaneda zu, der breites Aufsehen erregte und als einer der frühesten abolitio-

7 Tristan, Flora: Pérégrinations d’une paria. Paris: Arthus Bertrand 1838, Bd. 2, S. 462. 
nistischen Romane angesehen werden darf - lange vor Harriett Beecher Stowes 1852 erstmals veröffentlichtem Onkel Toms Hütte: ihrem 1839 niedergeschriebenen und 1841 veröffentlichten Roman mit dem auf den ersten Blick etwas enigmatischen Titel Sab! Es handelt sich um einen in vielfacher Hinsicht ganz anders konzipierten Text, der die große Breite an kreativen Schreibmöglichkeiten der kubanischen Autorin aufzeigt. Dabei zeigen sich zugleich auffällige Parallelen zu vielen anderen Texten des kubanischen 19. Jahrhunderts, insbesondere zu Cirilo Villaverdes Cecilia Valdés, einem Roman, mit dem wir uns noch beschäftigen werden und der auf Kuba zu einer Art Nationalroman avancierte.

Mit Cecilia Valdés verbindet Gómez de Avellanedas Sab nicht allein die Tatsache, dass der Text ebenfalls aus Kuba stammt, der Gattung des Romans und leicht einer romantischen Tradition zuzuordnen ist, sondern auch, dass er auf die Darstellung einer gesellschaftlichen Totalität abzielt und die realgeschichtliche Situation auf der Insel nicht nur literarisch erfassen, sondern auch zutiefst verändern möchte. Vergessen wir dabei nicht, dass der Roman in Spanien, also weitab von ihrer geliebten Insel Kuba entstand und damit entfernt von jener Sklaverei, welche von der kubanischen Dichterin in diesem Prosatext vehement angeklagt wird! Es handelt sich wie bei Cecilia Valdés um einen abolitionistischen Roman, welcher der Darstellung der Problematik der nicht-weißen Bevölkerungsgruppen große Aufmerksamkeit schenkt und den kolonialspanischen Behörden auf Kuba nicht genehm sein konnte. Folgerichtig wurde Sab von der Zensur im Jahr 1844 verboten.

Und doch sind bei allen Parallelen die Unterschiede zwischen beiden Romanen nicht weniger wichtig: Sab steht zwar ebenfalls in einer romantischen Tradition, lässt sich innerhalb dieser aber nicht dem historischen Roman im Sinne eines Walter Scott zuordnen, sondern der sogenannten „novela sentimental", die in eine literarhistorische Filiation mit Bernardin de Saint-Pierres Paul et Virginie, Rousseaus Julie ou La Nouvelle Héloïse oder Chateaubriands Atala sowie Les Natchez, aber auch Goethes Werther zu bringen ist. Keinesfalls beiläufig ist, dass es sich nicht um einen Roman eines männlichen Autors handelt, in dessen Mittelpunkt wie bei Villaverdes Cecilia Valdés eine schöne Mulattin steht, sondern um den Roman einer kubanischen Autorin, die ins Zentrum ihres Textes einen schönen Mulatten, eben Sab, als Titelfigur des Romans stellte. So dürfen wir vorab bereits festhalten: Mit Gertrudis Gómez de Avellaneda ist die Frau vom Objekt zum Subjekt des Schreibens geworden, die ihrerseits wiederum - in einer Art chassé-croisé - den schönen Mann zum Objekt ihres schreibenden Begehrens macht. Sehen wir uns dieses literarische Spiel mit den konventionellen Gendergrenzen einmal näher an!

Wir sollten uns an dieser Stelle nochmals in Erinnerung rufen, dass die kubanische Dichterin in ihrer Zeit eine Ausnahmestellung für sich beanspru- 
chen durfte. Denn schreibende Frauen gab es zwar weitaus mehr, als in unseren Literaturgeschichten auftauchen; doch erfolgreiche schreibende Frauen waren noch im 19. Jahrhundert zweifellos die Ausnahme. Innerhalb der romantischen Literaturen nehmen dabei Reiseschriftstellerinnen eine Ausnahmeposition ein, sind doch Flora Tristan, Ida Pfeiffer und viele mehr Autorinnen auf einem Terrain, das mehr und mehr auch von reisenden Frauen beansprucht wurde. Im Feld der Literatur aber stellen Dichterinnen und Schriftstellerinnen eine Minderheit dar, was kein Zufall ist, insofern die Literaturgesellschaften der amerikanischen wie der europäischen Länder ebenso wie diese Gesellschaften selbst von Männern beherrscht werden - auch wenn Gertrudis Gómez de Avellaneda keineswegs die einzige schreibende Frau war. In unserer Vorlesung wird sie jedenfalls nicht die einzige bleiben!

Daher ist es bedeutsam, dass es eine Frau ist, die mit Sab einen männlichen Helden zur Titelfigur macht und im Übrigen später mit dem Roman Guatimozín einen nicht weniger marginalisierten Helden, den historischen Cuauhtémoc, in den Protagonisten eines weiteren Textes über die Zeit der neuspanischen Conquista verwandeln wird. Die schöne Cecilia Valdés war als Mitglied der Kolonialgesellschaft, als Angehörige der nicht-weißen Bevölkerungsgruppen und als Frau dreifach diskriminiert. Sab wie auch der edle Indianer Guatimozín sind ebenfalls Vertreter marginalisierter beziehungsweise unterdrückter und einem Eroberungsprozess unterworfener ethnischer Gruppen, werden aber durch ihr Geschlecht keineswegs diskriminiert - zumindest nicht auf den ersten Blick.

Zur Rolle der Protagonistinnen als Symbolfiguren für die zu bildenden Nationen bzw. - im Falle von Cecilia Valdés - für einen angestrebten Nationenbildungsund Fusionsprozess gibt es bereits wichtige Untersuchungen, deren Ergebnisse in die Vorlesung eingeblendet wurden. ${ }^{8}$ Wie aber steht es mit dem Identifikation- und Symbolwert männlicher marginalisierter Figuren, die nicht weniger tragisch enden und zu Opfern jener gesellschaftlichen und rassistischen Ausbeutung werden, die ihre kolonialen (oder auch unmittelbar postkolonialen) Gesellschaften prägen? $S a b$ ist zwar bis heute ein durchaus bekannter Roman geblieben, zu einer gesellschaftlich wirkungsvollen Symbolfigur aber avancierte sein Titelheld nicht. Warum konnte sich die Leserschaft nicht mit diesem Helden, diesem schönen, großherzigen und gebildeten Mulatten aus Tulas Feder identifizieren?

Zur möglichen Beantwortung dieser Fragen ist eine genauere Analyse des Romans notwendig. Dabei wollen wir uns diesmal nicht allzu lange in paratextuellen Gefilden aufhalten, auch wenn es im kurzen Vorwort einiges Bemerkens-

8 Vgl. Sommer, Doris: Foundational Fictions. The National Romances of Latin America. Berkeley: University of California Press 1991. 
werte gäbe. Erwähnt sei nur, dass in den „Dos palabras al lector“, den „Zwei Worten an den Leser“, in romantischer Geste darauf hingewiesen wird, dass der Grund für die Niederschrift dieses Textes darin bestand, sich in Augenblicken der Muße und Melancholie zu zerstreuen, ohne dass bereits an eine Veröffentlichung gedacht worden wäre. ${ }^{9}$ Erst wohlmeinende Freunde hätten zu einer Publikation des Erzähltextes geraten. Wenn wir dies glaubten - und angesichts der kindlichen Zerstreuungsweisen der Autorin ist dies nicht unwahrscheinlich -, dann wären wir auf eher beiläufige Weise in den Genuss einer nicht unkomplizierten, für den Rassismus auf Kuba, in der Area der Karibik und der spanischsprachigen Welt durchaus aussagekräftigen Liebesgeschichte gekommen.

Wir legen den Paratext jedoch beiseite und wählen diesmal eine andere Annäherung an unseren literarischen Gegenstand. Gleich im ersten Kapitel treffen die beiden ungleichen Widersacher um die Liebe der schönen (und natürlich weißen) Carlota zusammen: der Sohn eines zu Reichtum gekommenen englischen Händlers, Enrique Otway, und sein nicht weniger schöner, aber mulattischer Widerpart Sab. Letzterer hat gleichsam als Vorahnung ein Lied über traurige Liebe auf den Lippen, als er seinem ihm bislang noch unbekannten Gegenspieler begegnet, ja diesen sogar zum Haus der von ihm so sehr geliebten Schönen führt. Die letzte Strophe von Sabs Liedlein wird abgedruckt - ein recht interessantes Beispiel dafür, wie bestimmte volkskulturelle Elemente bei den diesbezüglich sensibilisierten Romantikern Eingang in die ,hohe“ Literatur fanden: „Ne kleine Braune bringt mich um, / habt Mitleid mit mir, / denn sie schert sich nicht drum, / auch wenn sie’s Liebste mir.“10

Und in der Tat: Niemand wird im Roman Mitleid mit dem schönen Sab haben! Es wird innerhalb der Romanhandlung zwar eine Weiße sein, die diesen „Moreno“ ins Grab bringt, aber auf Mitleid in seinen Liebesqualen wird er ebenso wenig stoßen wie der Liebhaber in seinem volkskulturellen Lied. Eine Fußnote der Autorin weist hierbei die (offenkundig eher spanisch imaginierte) Leserschaft darauf hin, dass es den Kubanern dank ihrer reizvollen Sprache stets gelänge, selbst noch dem Trivialsten etwas Neues abzugewinnen. Auch in diesem Roman begleitet folglich eine erzählerische kommentierende Instanz den Text paratextuell mit Hilfe von Fußnoten. Doch sehen wir uns einmal das Porträt des Mulatten, das dem Lesepublikum gleich zu Beginn des Romans präsentiert wird, etwas genauer an: Wir können viel daraus lernen!

9 Gómez de Avellaneda, Gertrudis: Sab. Edición, prólogo y notas de Carmen Bravo Villasante. Madrid: Ediciones Anaya 1970, S. 37.

10 Ebda., S. 41: „Una morena me mata / tened de mi compasión / pues no la tiene la ingrata / que adora mi corazón.“ 


\begin{abstract}
Er schien kein weißer Kreole zu sein, aber auch kein Schwarzer, und man hätte ihm auch nicht geglaubt, dass er von den ersten Bewohnern der Antillen abstammte. Sein Antlitz präsentierte eine eigenartige Zusammensetzung, und man entdeckte in ihm die Kreuzung zweier verschiedener Rassen und dass sich in ihm, um es so auszudrücken, die Züge der afrikanischen Kaste mit denen der europäischen vermischten, ohne dass er doch ein perfekter Mulatte gewesen wäre.

Seine Hautfarbe war ein ins Gelbliche spielendes Weiß mit einem gewissen dunklen Hintergrund; seine breite Stirne war von ungleichen Strähnen von schwarzem, glänzenden Haar bedeckt, das den Federn des Raben glich; er hatte eine Adlernase, aber seine Lippen waren dick und bläulich dunkel und verrieten seine afrikanische Herkunft, er besaß einen vorstehenden dreieckigen Bart, große, etwas geschlitzte schwarze Augen unter horizontalen Augenbrauen, und in ihnen brannte das Feuer der ersten Jugend, wenn sein Antlitz auch leichte Furchen durchzogen. Die Gesamtheit dieser Züge bildete eine Physiognomie, eine Charakteristik, eine jener Physiognomien, welche vom ersten Augenschein an den Blick auf sich ziehen und niemals mehr, hat man sie erst einmal gesehen, in Vergessenheit geraten. ${ }^{11}$
\end{abstract}

In dieser Passage ist unschwer zu erkennen, dass der Rasse-Begriff hier keineswegs nur kulturell konnotiert ist, wenn auch das kulturelle Verständnis von „raza“ im spanischsprachigen Raum bis heute eine starke Dominanz besitzt. In Gómez de Avellanedas Roman wird der Begriff zweifelsohne biologisch und zugleich negativ wertend verwendet, wenn von der sogenannten afrikanischen Rasse die Rede ist. Dies ist selbst in einem abolitionistischen, für die Freiheit der Sklaven eintretenden Romantext der Fall; ganz in der Art, in welcher auch in Cirilo Villaverdes Cecilia Valdés eine Vielzahl durchaus rassistischer Beschreibungen vorkommt.

Wir sollten gleichwohl vorsichtig sein mit unserer Verurteilung der Autorin als ,Rassistin': Denn sie benutzt das Vokabular ihrer Zeit, um eine Physiognomie zum literarischen Ausdruck zu verhelfen, welche sie als schön und eindrucksvoll $\mathrm{zu}$ beschreiben versucht. Ich glaube nicht, dass vor den Augen einer Leserschaft des 22. Jahrhunderts unsere heutige Ausdrucksweise mehr Bestand hätte als jene des 19. Jahrhunderts, weichen wir doch selbst im Deutschen häufig auf den einem US-amerikanischen rassistischen Vokabular entstammenden Begriff „People of Colour“ aus, um nicht den deutschen rassistischen Begriff „farbig“ zu sagen. Und nennen wir in unseren Nachrichtensendungen doch die Vize-Präsidentin Kamala Harris in Nachahmung der US-Bezeichnung eine „Schwarze“, obwohl sie von ihrer Hautfarbe gewiss nicht dunkler ist als derjenige, der gerade zu Ihnen spricht. Es ist zweifellos nicht sehr glücklich, nur um deutsche Ausdrücke zu vermeiden auf das Vokabular eines Landes zurückzugreifen, das zweifellos rassistisch ist und in dem zu Beginn des 20. Jahrhunderts der gewählte Präsident Joe Biden

11 Gómez de Avellaneda, Gertrudis: Sab, S. 42. 
als US-Amerikaner irischer Herkunft als „Non-white“12 eingestuft worden wäre, da katholische Iren Säufer sein mussten und keine gutgläubigen angelsächsischweißen Christen sein konnten. Doch zurück zum Roman der Avellaneda!

In dieser für das 19. Jahrhundert typischen physiognomischen Studie wird das Gesicht des jungen Sab wie ein Zeichensystem gelesen, das mit einem bestimmten Schönheitsideal verknüpft ist, von dem kleine Abweichungen konstatiert werden. Die Eröffnungseinordnung der Zugehörigkeit weder zu den weißen Kreolen noch zu den Schwarzen noch zur indigenen Bevölkerung der Antillen hatte diesen Spielraum eröffnet, innerhalb dessen nun wertende Abweichungen wie in einem wissenschaftlichen Diskurs fest-gestellt werden. Der Schweizer Johann Caspar Lavater, der 1801 im behäbigen Zürich verstorbene ,Erfinder‘ und Begründer der Physiognomie, dem ganze Heerscharen von Romanciers des 19. Jahrhunderts in ihren physiognomischen Beschreibungen von Romanfiguren folgten, hätte es sich nicht träumen lassen, wie aufmerksam und mit welchem Detailwissen auf Kuba seine Methode immer wieder neu auf einen gegenüber Europa wesentlich komplexeren Gegenstand angewendet wurde! Bereits das kurze Zitat aus der Präsentation von Sab zeigt uns genau, wie eng eine physiognomische mit einer charakterlichen Beschreibung Hand in Hand ging. Die rassistischen Implikationen ${ }^{13}$ einer solchen Methode, welche auf Grundlage einer biologischen Anlage auf kulturelle und individuelle Züge schließen zu können vorgibt, liegen auf der Hand.

Die von der Erzählerin vermerkten Abweichungen betreffen selbstverständlich weiße Europäer und deren Schönheitsideal, dem sich ebenso die Erzählerfigur wie ihre impliziten Leserinnen und Leser verpflichtet wissen. Aufschlussreich ist natürlich die Tatsache, dass die vektorielle Lektürerichtung dieser Gesichtssemantik stets in die Vergangenheit weist, also im genealogischen Sinne rückwärtsgewandt ist; ein Grundzug von Identitätsbestimmungen in Lateinamerika, welche fast immer eine retrospektive und weniger eine prospektive Grundtendenz besitzen. Denn es wird viel stärker gefragt, woher jemand kommt, als wohin dieser jemand gehen will.

Es ist vielleicht nicht ohne Interesse, dem Portrait dieses Mulatten eines jener Portraits entgegenzustellen, die Cirilo Villaverde seiner mulattischen Protagonistin widmete. Dann wird man rasch und ohne größere Schwierigkeiten feststellen, dass auch in diesem kubanischen Roman das Schönheitsideal europäischer Herkunft ist, verkörpert etwa von Adela, die den Inbegriff der klassisch-

12 Vgl. zur historischen Entwicklung dieses rassistischen Vokabulars in den USA Painter, Nell Irving: A History of White People. New York - London: W.W. Norton 2009.

13 Vgl. Lévi-Strauss, Claude: Race et histoire. Suivi de L'œuvre de Claude Lévi-Strauss par Jean Pouillon. Paris: UNESCO - Editions gonthier 1961. 


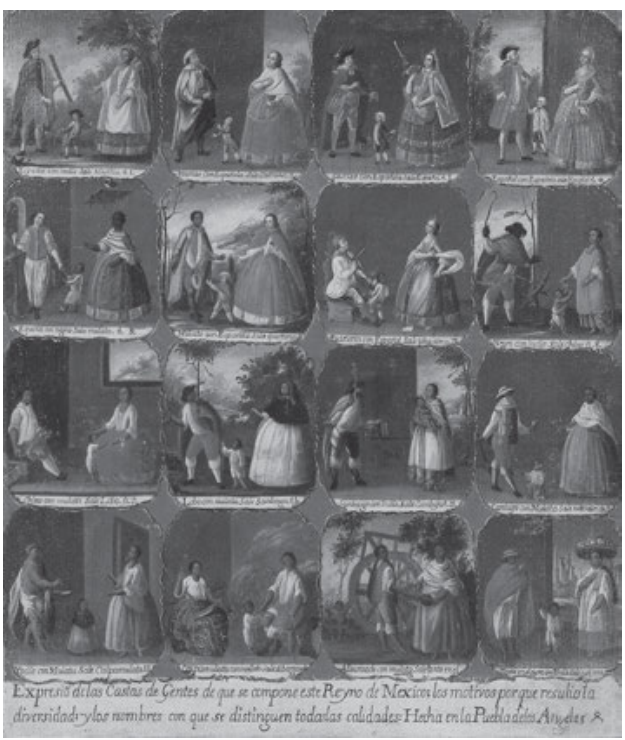

Abb. 38: „Pintura de Castas“, ca. 1750.

antiken Schönheit repräsentiert, da sie - die legitime Tochter Gamboas - mit einer griechischen Venus verglichen wird, während Cecilia von ihrem Äußeren her bestenfalls die „virgencita de bronce“ sein kann. Diese „bronzene Jungfrau“ übt freilich durch ihr Feuer, das auch in den schwarzen Augen Sabs aufglimmt, eine ganz andere, sexuelle Attraktion auf die Männer aus, die nicht in einer Art interesselosen Wohlgefallens wahrgenommen werden kann. Bei einem Mann wie Sab glüht dieses Feuer allerdings vergeblich.

Die aufmerksame Beschreibung des Phänotyps gibt in $S a b$ innerhalb einer rassistischen Gesellschaftskonzeption die Leitlinie des Romans vor: die Benachteiligung des Mulatten gegenüber allen weißen Protagonisten - auch wenn er sie an Charakterstärke, Ausdauer, Treue, Bildung und Intelligenz zum Teil weit hinter sich lässt. Das ist in den Augen der kubanischen Schriftstellerin kein Wunder: Die Mutter Sabs wurde frei im Kongo als Prinzessin geboren - darunter ging es nicht! Sab ist also von hoher, gleichsam adeliger Abkunft. Und auch von der Seite des Vaters her ist er - wie die Leserschaft gerne erfährt - nicht das Kind irgendeines Weißen: Sein Vater ist der Bruder des Vaters der schönen Carlota, auch wenn Sab selbst seinen leiblichen Vater nie kennengelernt hat. ${ }^{14}$ Als unehelicher Sohn von Don Carlos gehört Sab sozusagen zur Familie: Er befindet sich zu Recht - wie es 
der Brasilianer Gilberto Freyre ${ }^{15}$ in seiner klassischen Studie formuliert hätte - in der „Casa Grande“ und nicht in der „Senzala“, also im Herrenhaus und nicht in der Sklavenbaracke.

Es verwundert nicht, dass das Thema der Ausbeutung von Sklaven und ihres schrecklichen Lebens in Unfreiheit und völliger Abhängigkeit zum ersten Mal im Roman nicht im Erzählerdiskurs, sondern im Diskurs Sabs eingeführt wird. ${ }^{16}$ Selbst ein Opfer von Unterdrückung und Ausgrenzung, ist er sensibel für die innerhalb der Skala der Ausgeplünderten noch unter ihm Stehenden, auch wenn er mit ihnen das Los der Versklavung teilt. Er deutet auf das Schauspiel einer „humanidad degradada“, einer degradierten Menschheit und das von Menschen, die wie Vieh behandelt würden ${ }^{17}$ - eine fürwahr überraschende Äußerung im Munde eines Menschen, der als „Mayoral“ auf dem „Ingenio“, der Zuckerrohrplantage von Carlotas Vater, eingesetzt ist! Diese Worte, so werden wir im weiteren Fortgang der Romanhandlung sehen, sind keineswegs zufällig: Sab vermag sehr präzise die eigene Situation wie auch das gesamte System einer Ausbeutung durch Sklaverei und der kolonialen Wirtschaft einzuschätzen, das nur wenigen ein Leben in Wohlstand garantiert.

Dieses Wissen macht uns auf die Zwischenposition des Mulatten nicht allein in rassisch-physiognomischer, sondern auch in sozialer und politischer Hinsicht aufmerksam: Er gehört weder den Weißen noch den Schwarzen an. Sab ist zwar Sklave, aber auch „Mayoral“, beklagt das Schicksal der versklavten Schwarzen, ist zugleich aber zum Aufseher über sie eingesetzt, will eine gerechtere Gesellschaft, kann aber doch nicht - und der Roman bietet ihm in seinem weiteren Verlauf reichlich Gelegenheit dazu - aus seiner Rolle als „dominant-dominé“, als unterdrückter Unterdrücker heraus. Zwischen Sklavenhaltern und Sklaven wird Sab überdies in seiner Liebe zur Sklavenhalter-Tochter Carlota, mit der er zusammen aufgewachsen ist und erzogen wurde, buchstäblich zerrieben und zerquetscht.

Und doch ist seine Figur so gezeichnet, dass sie alle anderen an Größe überragt. Er ist von Gertrudis Gómez de Avellaneda mit Recht zur Titelgestalt erkoren worden. Sab hat mit Carlota die Bücher geteilt, doch wisse er sehr wohl, dass er als Sklave geboren sei. Trotz alledem erklärt er dem ihm noch fremden Enrique Otway: Als Sklave sei er geboren und als Sklave wolle er Carlota dienen und für

15 Vgl. Freyre, Gilberto: Casa Grande \& Senzala. Formação da família brasileira sob o regime de economía patriarcal. 4a. edição, definitiva. Ilustrações de Tomaz Santa Rosa. 2 Bde. Rio de Janeiro: Livraría José Olympio Editora 1943.

16 Gómez de Avellaneda, Gertrudis: Sab, S. 44.

17 Ebda., S. 45. 


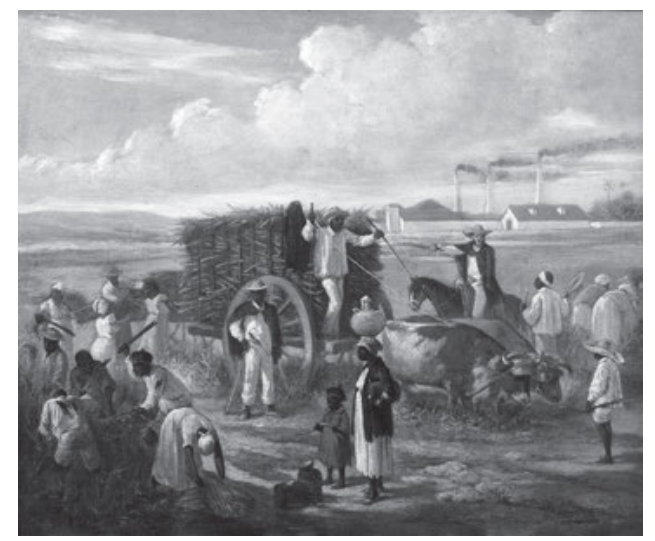

Abb. 39: „Corte de caña“, Öl auf Leinwand von Víctor Patricio Landaluze, 1874.

sie sterben. ${ }^{18}$ Erneut tut sich auf dieser Ebene eine Zwischenstellung auf: Sab hat einerseits Anteil an der realen Sklaverei, deren Opfer er ist, andererseits aber auch an der metaphorischen Sklaverei des Liebesdienstes an seiner Herrin Carlota, zu deren Opfer er noch wird.

Sklaverei ist in diesem kubanischen Roman also in einem doppelten Sinne zu verstehen. Genau hierin liegt eine der reizvollen Seiten dieses Erzähltextes und zugleich jener Aspekt, welcher die metaphorische Ausweitung der Problematik der Sklaverei auch auf eine Leserschaft ermöglicht, die selbst von der realen und wirtschaftlich für die Zuckerrohrinsel relevanten Sklaverei zumindest nicht direkt betroffen ist.

All dies wird bereits im ersten Kapitel des Romans eingeführt, ein Kapitel also, das seine die zentralen Isotopien entwerfende Funktion innerhalb der Narration bestens erfüllt. Es macht auch klar, worin die Problematik der geplanten Heirat Carlotas mit Enrique jenseits der unerwidert bleibenden Liebe Sabs zur schönen, reichen und glücklichen Erbin eines Ingenio besteht: Enrique ist der Sohn eines wirtschaftlich aufstrebenden, wenn auch in Schwierigkeiten gekommenen ausländischen Aufsteigers, während Carlota die Tochter eines ehedem sehr reichen, nun aber wirtschaftlich immer mehr gefährdeten einheimischen Kreolen ist.

Dank einer derartigen Anlage wird zugleich die wirtschaftliche Problematik der Insel ins Blickfeld gerückt und eine Perspektive besserer wirtschaftlicher Nutzung zumindest angesprochen: die eines größeren britischen Einflusses, der freilich - wie der weitere Fortgang des Plot am Ende zeigen wird - zu einem gewissen Identitätsverlust und zu einer Entwurzelung Carlotas führen wird. Längst hat

18 Ebda., S. 49. 
das effizientere britische Kolonialsystem das spanische überholt. Andererseits ist das französische Modell angesichts des Traumas der Haitianischen Revolution als Vorbild ausgeschieden: Die koloniale Ausbeutung Kubas wird niemals so radikale Züge mit einer so starken Vermehrung der schwarzen Sklaven-Bevölkerung aufweisen wie die Saint-Domingues - diese Lektion haben die spanischen Sklavenhalter gelernt!

In der Karibik liegen die verschiedenen europäischen Kolonialsysteme dicht nebeneinander und die Avellaneda hat dieses Faktum anhand der Personenkonstellation geschickt in ihren Roman eingebaut. Für Enrique Otway wird das schöne Kuba nie die vollgültige Stelle der Heimat einnehmen. Und Carlota wird ihm in die Fremde folgen müssen, fern von ihrer Insel, ohne doch die Liebe zu finden, nach der sie suchte. All dies bietet eine interessante, die verschiedenen Kolonialsysteme miteinander vergleichende Perspektive, die im Roman freilich nur angedeutet, nicht aber ausgeführt ist. Doch nicht umsonst wurde Enrique, wie der männliche Held in Jorge Isaacs María, nach England zur Ausbildung geschickt, um von dort einen weiteren Blick auf die wirtschaftlichen Dinge zu erhalten als vom kolonialen Mutterland Spanien aus.

Die Liebe zwischen Enrique und Carlota steht - wie so oft im lateinamerikanischen Roman des 19. Jahrhunderts - unter einem unglücklichen Stern. Von Enriques Vater aus klugem Kalkül eingefädelt, von Carlotas Vater wegen der Herkunft des Schwiegersohnes zunächst abgelehnt, wird die Hochzeit von Carlota selbst erzwungen, da sie in eine melancholische, ihr Leben bedrohende, typisch romantische Krankheit verfällt. Diese findet erst dann ihr Ende, als man der jungen und hübschen Frau verspricht, dass sie an ihrem achtzehnten Geburtstag den schönen Enrique heiraten dürfe. Für eine Liebesheirat wäre damit der Weg frei ...

Doch Enrique Otway sind Geschäfte wichtiger als die Liebe - kein Wunder, ist er doch aus spanischer Sicht ein allein am geschäftlichen Erfolg ausgerichteter Brite. Kaum auf dem väterlichen Ingenio seiner Geliebten angekommen, kündigt er schon wieder seine baldige Abreise aus geschäftlichen Gründen an, was den romantischen Liebesdiskurs mit erhobenem Zeigefinger unserer leidenschaftlichen Kreolin, unserer „apasionada criolla“19 hervorruft:

Was denn: Nicht einmal sieben Tage Unterschied? Sieben Tage, Enrique! So viele Tage habe ich Dich während unserer ersten Trennung nicht gesehen, und alles erschien mir wie eine Ewigkeit. Hast Du denn nicht erfahren, wie traurig es ist, die Sonne einen Tag nach dem anderen aufgehen zu sehen ..., ohne dass sich die Finsternisse des Herzens auflösten, wenn die Tage uns keinen Strahl der Hoffnung schenken ..., weil wir wissen, dass wir in diesem

19 Ebda., S. 70. 


\begin{abstract}
Lichte nicht das geliebte Antlitz wiedersehen? Und danach, wenn die Nacht hereinbricht, wenn die Natur inmitten der Schatten und der lauen Lüfte einschläft, hast Du da nicht gefühlt, wie sich Dein Herz mit einer süßen Zärtlichkeit füllt, die so unbestimmbar ist wie das Aroma der Blumen? ... Hast du da nicht erlebt, wie notwendig es ist, die geliebte Stimme inmitten des Schweigens der Nacht zu hören? Hat Dich nicht diese Abwesenheit ausgelaugt, dieses ständige Unwohlsein, diese unermessliche Leere, diese Agonie eines Schmerzes, der sich unter tausend verschiedenen Formen wiederholt, aber stets doch drängend, unauslotbar, unerträglich ist? ${ }^{20}$
\end{abstract}

Die rhetorischen Fragen dieses romantischen Liebesdiskurses weisen letztlich ins Leere, aber die junge Frau bietet alles an Ausdrucksmöglichkeiten auf, was sich im Zeichen der Romantik um die Gefühle der Liebe versammelt hatte. ${ }^{21}$ Doch ihr Enrique entspricht nicht diesem Bild eines von Liebesschmerzen zerfressenen Herzens, das jenem Vers aus Alphonse de Lamartines Gedicht Le lac gehorchen zu wollen scheint: „Un seul être vous manque / et tout est dépeuplé.“ „Ein einzig Wesen fehlt, und alles ist entvölkert“ - sicherlich eine jener romantischen Liebesformeln, die bis heute nicht vergessen sind!

Carlotas Liebeskonzeption - wie schon ihre Krankheit - ist romantisch konzipiert und von ausgiebigen Lektüren genährt. Wir stoßen an dieser Stelle erstmals auf die Figur einer in Romanen und Gedichten bewanderten Heldin, deren Gefühle unmittelbar im Zeichen der Romantik aufwallen, die ihre gesellschaftliche Sozialisation folglich durch die persönliche Aneignung von Büchern bewerkstelligt, welche ihre Gefühlswelt gleichsam vorprogrammieren. Gustave Flaubert wird dieser Figur in Madame Bovary ein literarisches Denkmal setzen, welches ähnlich erfolgreich war wie jenes des allzu belesenen Ritters, dem Miguel de Cervantes in Don Quijote de la Mancha sein Monument zum Abschiedsgruße entbot. Carlota lebt, was sie gelesen: Liebe und Lesen sind für sie die beiden Seiten einer unhinterfragbaren Seins-Erfahrung, die im Nacherleben des Gelesenen ihren Nährboden wie ihre letzte Legitimation findet. Ihr Name, so dürfen wir vermuten, deutet auf Goethes Werther.

Innerhalb eines allgemeinen Weltschmerzgefühls kommt dem Organ des Herzens, kommt der Liebe die entscheidende Rolle als Lebenskraft zu - als ,vis vitalis“. Versiegt oder scheitert die Liebe, ist das Leben fürderhin sinnlos: Wie bei Werther tritt der Tod in sein Recht. Es fällt aber auch nicht schwer - und die Sekundärliteratur hat es ausführlich getan -, hinter dieser Charakterzeichnung Carlotas die Lebenserfahrung der realen und in romantischen Lektüren erfahrenen Autorin zu suchen, derartige Passagen also mit Blick auf Gertrudis Gómez de

20 Ebda., S. 69.

21 Vgl. hierzu Band 2 der Reihe „Aula“ von Ette, Ottmar: LiebeLesen, 389-419. 
Avellaneda autobiographisch zu lesen. Lesen und Leben lassen sich nicht einfach wieder voneinander trennen!

Nicht unwichtig ist im Kontext unserer bisherigen Überlegungen aber auch die Tatsache, inwieweit sich der Liebesdiskurs mit dem Naturdiskurs der Romantik verbindet und insbesondere die Korrespondenznatur sich in einen direkten Bezug zur gefühlten, empfundenen oder geteilten Liebe einbringt. Kein Zweifel: Der gutaussehende, aber zu geschäftstüchtige Enrique Otway kann auf dieser Ebene nicht mithalten, wohl aber die junge Carlota, deren Figur und Figurierung auf die für den romantischen Diskurs als Lebenshaltung und Lebensentwurf zentralen Nexus zwischen Liebe, Lesen und Natur nicht verzichten kann und darf! Diesen Beziehungsreichtum zwischen Natur und Gefühlswelt sehen wir sogleich auf einer noch intensiveren Stufe im Roman verwirklicht.

In einer Gefühlslage, wie sie Carlota in ihrer nur lau erwiderten Liebe $\mathrm{zu}$ Enrique empfindet, ist ein tropisches Gewitter allemal nicht weit entfernt. Und in der Tat brauen sich am Horizont bereits schwarze Wolken zusammen, wobei es einer karibischen Autorin nicht schwerfallen kann, die romantischen Gewitter Europas orkanartig zu überbieten. So regnet es wieder einmal im hispanoamerikanischen Roman; und zwar nicht im Sinne eines englischen Sprühregens, sondern mit der ganzen Wucht tropischer Unwetter. Enrique - in England erzogen - unterschätzt die Gefahr und lässt sich nicht von der Abreise abbringen: Sab muss ihn begleiten und damit seine Gefährdung teilen. Damit kommt es zum zweiten gemeinsamen Reiseweg von Sab und Enrique, der beiden Widersacher um die Liebe der schönen Carlota, nun aber im Bewusstsein der Rivalität, die sich immer weiter steigert. Zudem weiß Sab mittlerweile - Enrique hatte dies unvorsichtigerweise ausgesprochen, als er sich allein und unbelauscht glaubte - um die interessegeleiteten, vor allem am Geld der vermeintlich reichen Erbin ausgerichteten Gelüste des jungen Briten. Gewiss liebt Enrique die schöne Kreolin; doch größer noch ist seine Liebe zum Geld, seine Habgier, die am Ziel eines Lebens in Komfort und Luxus ausgerichtet ist. Wird die Liebe oder das Geld obsiegen?

Das tropische Gewitter bricht los, dicke Äste fallen herab und treffen Enrique, der ohnmächtig und blutüberströmt ins Gras sinkt. Wir wissen bereits aus Chateaubriands Atala, mit welcher Gewalt Bäume vom Blitz getroffen herabstürzen können und in welcher Beziehung dieses Umfallen der Bäume zur sexuellen Potenz oder Impotenz der entsprechenden Liebhaber steht. Die Freud'sche Traumsymbolik mit ihrer psychoanalytischen Traumdeutung wird erst mit dem neuen Jahrhundert erscheinen und diese herkömmliche Sexualsymbolik literarisch desavouieren. Sie sehen: Es gewittert sehr in den amerikanischen Tropen! Sab hat es nun in der Hand, sich seines Widersachers ein für alle Mal zu entledigen, ohne dass man ihm an Enriques eventuellem Tod die Schuld geben könnte. Es wäre ihm möglich, so heißt es im Roman, Enrique „a la nada“ zu reduzieren, also ins Nichts 
zu katapultieren. ${ }^{22}$ Wird der junge, verliebte Sab dieser Versuchung, mit einem Mal all seine Probleme zu lösen, widerstehen können?

Doch die Worte Carlotas, die Sab das Schicksal Enriques anvertraute, geben den Ausschlag: Die moralische Integrität des jungen Mannes hat die Probe bestanden; und so bleibt Carlota ihr umschwärmtes Objekt romantischen Begehrens erhalten. Sab hat Enrique gerettet, Carlota fällt ihm um den Hals und fordert, dass man ihn baldmöglichst und nicht erst anlässlich seines fünfundzwanzigsten Geburtstages freilasse. Damit fände zwar eine Befreiung des Sklaven aus der realen Sklaverei, nicht aber aus der metaphorischen Sklaverei der Liebe statt: Sab küsst Carlotas Hand, doch diese zieht sie schnell unter dem brennenden Kuss des Mulatten zurück. Die Qualen Sabs gehen weiter, ${ }^{23}$ denn die Verlustangst hat Carlotas Liebe zu Enrique nur noch mehr entfacht und gegenüber der Liebe Sabs umso blinder gemacht.

Am nächsten Morgen hat sich das Gewitter verzogen. Wir sehen Carlota, die wie ein unschuldiges Kind durch ihren Garten Eden geht: umgeben von Blumen, inmitten einer idyllischen Landschaft, in welcher alles in Harmonie scheint. Tauben sitzen auf den Schultern der Vögel fütternden schönen Frau, die einen Schmetterling einfängt und beschwingt wieder freilässt. ${ }^{24}$ Daneben denkt Carlota aber durchaus auch einmal über das schreckliche Los der Sklaven nach, die mitansehen müssen, wie ihre eigenen Kinder als Waren verkauft werden. Sie hofft, dereinst alle Sklaven freilassen zu können, wenn sie erst einmal Enrique geheiratet haben wird. ${ }^{25}$ Die Berechnungen Enriques freilich sehen gänzlich anders aus ...

Carlota träumt von Liebe und baldiger Hochzeit. Innerhalb einer exotisierenden romantischen Grundstimmung fragt sie sich, was ihnen am Reichtum liege, sei doch eine einfache „choza“, eine schlichte Hütte, genug für Die beiden Liebenden. Dies ist eine fürwahr grundlegende Verkennung Enriques! Und doch wird zugleich deutlich, dass Sab einer solchen Liebeskonzeption zweifellos entsprochen hätte. Sab, dies ist den Leserinnen und Lesern längst klar, wäre der jener romantischen Liebe Carlotas in Wahrheit würdige Liebespartner. Zugleich verweist die „choza“ darauf, dass in Avellanedas Roman ein exotisiertes und zugleich exotisches Ambiente aufgerufen wird, das den Roman in eine Tradition mit Bernardin de Saint-Pierres Paul et Virginie und Chateaubriands Atala ein-

22 Gómez de Avellaneda, Gertrudis: Sab, S. 78.

23 Ebda., S. 81.

24 Ebda., S. 87.

25 Ebda., S. 88. 
rückt: Carlotas Liebe und das einfache Leben in der Indianerhütte. Doch Enrique geht es um das Ingenio, um die Erwirtschaftung von Mehrwert und Gewinn.

Freilich gibt es im Roman zugleich eine grundsätzlich andere Perspektivierung: Denn aus Sicht einer gerade nach Spanien übersiedelten kubanischen Kreolin - und eine solche ist die junge Tula zweifellos - handelt es sich um das Exotische des Eigenen beziehungsweise um das Eigene als das für spanische Leserinnen und Leser Exotische. Ihr Roman setzt folglich eine Auto-Exotisierung aus der Ferne in Gang. Darum wohl auch die andere Perspektivierung der Kreolin Carlota, eines schönen und kranken Kindes ihrer romantischen Zeit. Denn die schöne Kubanerin Carlota ist nicht nur eine romantische Seele, sondern als Weiße und Tochter eines Plantagenbesitzers auch standesbewusst, kommt sie doch nicht einmal auf den Gedanken, dass Sab ihrer Liebe wert sein könnte. Da bleibt dem armen und naturverbundenen Mulatten im Roman nur die Zwiesprache mit einem Tier, das als einziges seine Zärtlichkeit versteht und erwidert.

Noch träumt Carlota von einem Leben voll unendlicher, nie versiegender Liebe. Doch scheint in ihrer Seele sich bereits das kommende Unheil auszudrücken, denn sie stimmt auf einer Gitarre ein trauriges Lied an. Auf die Leserschaft könnte dieses Lied wie eine direkte Replik auf das triste Liedlein von Sab wirken, das wie in einer Mise en abyme das nachfolgende Schicksal des Mulatten wie der Romanfiguren insgesamt vorwegnahm. Auch in Carlotas Gesang geht es um unglückliche Liebe: „Nike ist liebreich und jung, / und ihr Herz so fromm / trägt die unerschütterlich Neigung / für den schönen Damon.“26 Dass wir es auch an dieser Stelle mit einer volkskulturellen Prägung zu tun haben, wie sie für die Romantik charakteristisch ist, muss nicht eigens betont werden.

Im neunten Kapitel des Romans bricht die vielfach amourös und interessegeleitet verwobene kleine Gesellschaft nach Cubitas auf, was der Autorin erlaubt, einige Landschaftsbeschreibungen aus ihrer kubanischen Heimat in der Nähe von Camagüey, also im „Oriente“ Kubas, einzufügen. Der feurige Sab blickt bisweilen in die herrliche Landschaft, bisweilen auf die nicht weniger wunderbare Frau, die ihm in Harmonie mit der Landschaft, mit der sie umgebenden Natur erscheint: Natur und Frau sind beide so jung und schön, ,ambas tan jóvenes y hermosas“.27 Damit ist offenkundig die Vorstellung von einer noch jungen Natur in der Neuen Welt gemeint, eine Vorstellung, auf die wir bereits gestoßen waren, die selbst die Schriften Alexander von Humboldts nicht hatten verdrängen können und die von den Geographen des 18. Jahrhunderts in den Köpfen der Zeitgenossen für lange

26 Ebda., S. 103 f.: „Es Nice joven y amable / y su tierno corazón / un afecto inalterable / consagra al bello Damón.“

27 Ebda., S. 109. 
Zeit festgeschrieben worden war. Sie taucht unter der Feder der Romantiker auf beiden Seiten des Atlantiks immer wieder auf.

Die phantasiereichen und bisweilen grotesken Landschaftselemente sind in ihrer literarischen Beschreibung im Übrigen deutlich an der Traditionslinie Bernardin de Saint-Pierres ausgerichtet; und wie der französische Schriftsteller fügt die Autorin im Fußnotenteil Erläuterungen einzelner Objekte hinzu. ${ }^{28}$ Sab soll auf Bitten der kleinen Reisegesellschaft nun auch noch eine wunderbare Geschichte erzählen, und er tut dies, indem er auf Martina in Cubitas hinweist, die sich von indianischen Vorfahren aus der präkolumbischen Zeit der Insel herleitet. Sie wird damit zur Vertreterin einer - wie es im Roman heißt - „raza casi extinguida en esta isla“, also einer auf der Insel fast ausgelöschten Rasse. ${ }^{29}$ Die alte Martina wiederum erzählt Sab vom barbarischen Tod, den die spanischen Eroberer dem indianischen Kaziken Camagüey bereitet hätten, ${ }^{30}$ wodurch die indigenen Kulturen zumindest als Hintergrundfolie mitsamt der spanischen Conquista in den Roman eingeblendet werden.

Diese Geschichte ist eine wunderbare Erzählung und erfüllt die Kriterien des „maravilloso“. Denn Camagüey - dessen Name jener Provinz, der die Avellaneda entstammt, den Namen verlieh - sei unweit von hier vom Felsen gestürzt worden, worauf sich sein Blut über die Erde vergoss, weshalb die Erde in dieser Region auch so rot geblieben sei. Jede Nacht kehre Camagüey zu diesem Berg in Form jenes Lichtscheins zurück, den die Reisenden kurz zuvor erblickt hatten - ein typisch volkskulturelles Element von Mythen und Legenden, wie wir es in Esteban Echeverrías La Cautiva kennengelernt hatten. Kein Zweifel: Auch Chateaubriands Atala lässt grüßen! Diese ,wunderbare‘ Geschichte verwandelt sich im Medium der Literatur gleichsam unter unseren Augen in eine Legende und damit in eine volkskulturell tradierte Form, welche als solche wiederum in die ,hohe Literatur integriert werden kann.

In der Legende wird das Barbarische nicht den Indianern, sondern vielmehr den spanischen Eroberern zugewiesen - und Martina als Nachfahrin des noblen Kaziken erscheint als letztes Zeichen dieser edelmütigen Ureinwohner Kubas. In diesem Zusammenhang erhält vor allem ihre Prophezeiung Gewicht, dass der schon einmal mit Blut getränkte Boden noch ein weiteres Mal getränkt werden würde. ${ }^{31}$ Dann würden die Schwarzen die Rächer der auf der Insel ausgelöschten indianischen Ethnie sein. Dies ist eine Vorstellung, die sich aus der Feder Diderots

28 Ebda., S. 110.

29 Ebda., S. 112.

30 Ebda.

31 Ebda., S. 113. 
stammend übrigens in Guillaume-Thomas Raynals Histoire des deux Indes finden lässt, in einem europäischen Kolonialwerk des 18. Jahrhunderts also, dem wir bereits kurz in Fernández de Lizardis El Periquillo Sarniento sowie an anderen Stellen unserer Vorlesung begegnet waren.

An dieser Stelle wird Sab in seiner Erzählung unterbrochen, da man in Kuba seit den Ereignissen auf der Nachbarinsel - gemeint ist Haiti und die erfolgreiche Sklavenrevolution - niemals gerne derlei Sätze und Geschichten höre. Über der spanischen Kolonialgesellschaft schwebt die Drohung des seit Ende des 18. Jahrhunderts immer wieder als Gefahr beschworenen ,Rassenkrieges‘, der „guerra de razas“, in welchem sich die schwarzen Sklaven über ihre weißen Unterdrücker und zugleich über die spanische Kolonialverwaltung hinwegsetzen und sich für unabhängig erklären könnten. An diesem kritischen Punkt des Erzählvorgangs vergisst Carlota aber nicht hinzuzufügen, dass sie niemals ohne zu weinen die Geschichte der spanischen Eroberung habe lesen können ${ }^{32}$ - auch dies ein Element, das auf Guatimozín vorausweist, den späteren Roman der Avellaneda.

Die unschuldige Carlota weint wegen eben jener ,Rasse“ der Indianer, die einstmals auf jenem Boden gelebt hatten, auf dem sie sich gerade bewegt. Die indianische Präsenz ist bereits zu Beginn des 19. Jahrhunderts Vergangenheit, doch wird diese Vergangenheit im romantischen Diskurs zum Präsens einer fiktionalen Präsenz: In der dominikanischen Literatur von Manuel de Jesús Galván könnte uns der Erfolgsroman Enriquillo diesen Vorgang belegen.

In Gertrudis Gómez de Avellanedas Prosastück Sab wird die indigene Präsenz und Vergangenheit anschaulich in der Phantasie Carlotas, Enrique und sie seien Indianer und er würde für sie eine „choza“ bauen, eine kleine Hütte - eine Phantasie, die deutlich Spuren der Lektüre von Chateaubriands Atala aufweist, in dessen Tradition sich Tulas Roman in vielerlei Hinsicht einschreibt. Der Mulatte Sab seinerseits denkt, dass Carlota keineswegs weniger schön sei, wäre sie als Indianerin oder Schwarze geboren. ${ }^{33}$ Dies beinhaltet insoweit einen interessanten kulturvergleichenden Aspekt, als in diesen Formulierungen auf der weiblichen Seite die Schönheitshierarchie der ,Rassen` zumindest andeutungsweise aus der Perspektive Sabs in Frage gestellt wird.

Aufschlussreich ist aber auch, dass Sab nicht den indianischen Traum Carlotas träumt, sondern seine Phantasie, seinen Tagtraum nach Afrika projiziert, wo sich die beiden in einer anderen Welt lieben könnten. ${ }^{34}$ Es handelt sich dabei um eine überaus wichtige Passage, in welcher sich Kuba auf andere Welten und Zivili-

32 Ebda.

33 Ebda., S. 114.

34 Ebda., S. 114. 
sationsformen, auf indianische wie auf schwarze Kulturen hin öffnet - wenn auch nur in exotisierender Weise. An dieser Frage werden die drei unterschiedlichen Positionen unseres Dreiecks-Liebesverhältnisses deutlich gemacht; es spricht zunächst Carlota:

\footnotetext{
„Oh Enrique, ich beweine es, nicht damals geboren zu sein und dass Du, ein Indianer ganz wie ich, mir eine Hütte aus Palmen zimmertest, wo wir ein Leben voller Liebe, Unschuld und Freiheit hätten genießen können.“

Enrique lächelte über den Enthusiasmus seiner Geliebten und antwortete mit einer zärtlichen Geste; der Mulatte wandte seine Augen voller Tränen von ihr ab.

„Ah, ja!, dachte er, Du wärst nicht weniger schön, wenn du schwarze oder kupferfarbene Haut hättest. Warum hat dies der Himmel nicht gewollt, Carlota? Du, die Du das Leben und das Glück der Wilden verstehst, warum wurdest Du nicht mit mir in den glühenden Wüsten Afrikas oder in einer noch unbekannten Gegend Amerikas geboren?“35
}

Wie in einem Polylog spiegeln die Tagträume der Liebenden in unterschiedlicher Weise ihre Liebesphantasien hinein in die Pole der indianischen und schwarzen Kulturen, ohne dass diese freilich mehr wären als verschiedenartige Staffagen, unterschiedliche Decors der immer gleichen Liebessehnsüchte der Protagonisten. Aufschlussreich ist in diesem Zusammenhang die Tatsache, dass der Mulatte Sab ebenfalls das Dreigestirn weiblicher Schönheit (die Weiße, die Schwarze und die Mulattin) ganz so, wie wir es auf einer Abbildung vom Beginn des 19. Jahrhunderts ${ }^{36}$ sehen, im Kopf hat, nur dass die Mulattin von einer Indianerin mit kupferfarbener Haut ersetzt wird. Auch der junge Sklave Sab partizipiert an einem patriarchalischen Bild der Frau, wie es in den Sklavenhaltergesellschaften der Karibik üblich war, nur dass es bei ihm keine Hierarchie zwischen der weißen, der kupferfarbenen und der schwarzen weiblichen Schönheit gibt.

Bei diesem Dreigestirn handelt es sich offensichtlich nicht nur um eine individuelle männliche Obsession, sondern um einen wesentlichen Bestandteil des kollektiven männlichen Imaginären. Aufschlussreich ist des Weiteren, dass der Mulatte auf diesem Gebiet wiederum eine interessante Zwischenstellung selbst in seinen Phantasien einnimmt, sehnt er sich doch zugleich nach Afrika und an einen verborgenen Ort Amerikas: Zwischen beiden Kontinenten oszilliert seine eigene Identitätskonstruktion. Doch das System der kolonialspanischen Sklavenhaltergesellschaft zwingt ihn, Enrique nach der Ankunft in Cubitas eine gute

35 Ebda., S. $114 \mathrm{f}$.

36 John Gabriel Stedman: Narrative of a five years' expedition against the revolted Negroes of Surinam. London: J. Johnson \& J. Edwards 1796, Band II, Tafel VXXX. 


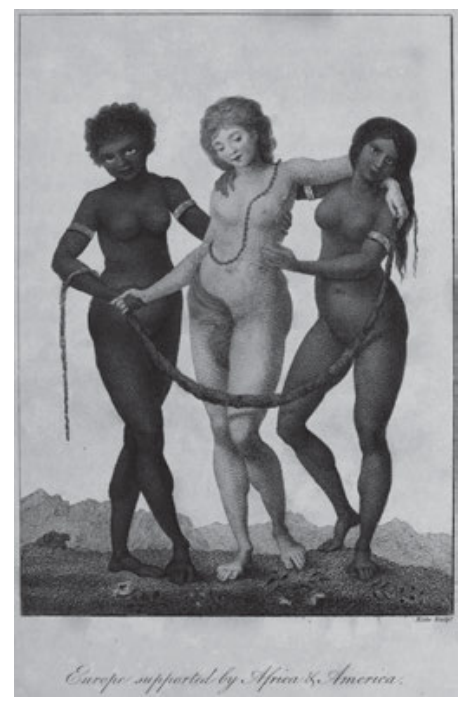

Abb. 40: „Europe supported by Africa and America“, Stich von William Blake nach einer Zeichnung von John Gabriel Stedman, 1796.

Nacht zu wünschen, ihn aber insgeheim wegen dessen nur mühsam überspielter Herzlosigkeit abgrundtief zu verwünschen.

Sab ist am folgenden Tag der Führer einer gefährlichen Wanderung durch die wunderschönen Höhlen von Cubitas, deren größte die der „Cimarrones“, also der entlaufenen schwarzen Sklaven, genannt wird. Sab trägt nicht nur erfreut Carlota auf seinen liebevollen Händen, sondern rettet erneut Enrique vor einem gefährlichen Sturz, ${ }^{37}$ so dass er einen erleichterten Blick der schönen Weißen als Dank ernten kann. Danach werden sie von der alten Indianerin Martina, die bis auf einen schwächlichen Enkel alle Nachkommenschaft verloren hat, in ihrer Choza zum Essen begrüßt. Dies verläuft nicht ohne eine Art „parodia de la hospitalidad“, eine Parodie der Gastfreundschaft: Die kubanischen Kreolen der Familie Carlotas nebst ihrer Begleiter besuchen die letzten Reste einer im Grunde längst ausgestorbenen Ethnie und beglaubigen damit deren Verschwinden auf der Insel. Gertrudis Gómez de Avellaneda erkennt der indigenen Bevölkerung zwar keinen eigenen kulturellen Status zu, vermeidet es aber, wie so viele andere die Indianer der Karibik totzuschweigen.

Unterdessen brauen sich Wolken diesmal nicht am Himmel, sondern im Herzen der schönen Carlota zusammen, die erkennt, wie wenig Enrique sie doch liebt. Eine geheime Stimme sage ihr, dass sie unglücklich sein werde, ${ }^{38}$ eine Vor-

37 Gómez de Avellaneda, Gertrudis: Sab, S. 120.

38 Ebda., S. 145. 
ahnung, die auch die unscheinbare und stets im Schatten Carlotas stehende Teresa ausspricht. Sie prophezeit ihr Ähnliches, wenn es ihr nicht endlich gelänge, die sie plagende extreme Empfindsamkeit, ihre „sensibilidad“, zu mäßigen und vernünftig zu werden. Mit dem Einschlafen Carlotas endet der erste Teil des Romans unheilschwanger.

$\mathrm{Zu}$ Beginn des zweiten und letzten Teils treffen sich Sab und Teresa nachts in einer tropischen Landschaft, wobei Sab der nun langsam zu einer eigenen Gestalt entwickelten Teresa seine Liebe zu Carlota gesteht. Er legt ihr seine Demütigungen als Sklave und Mulatte dar und weist sie darauf hin, dass es nur eines Mannes bedürfe, der den Sklaven sage „Sois hombres“, „Ihr seid Männer“, damit diese sich gegen die Ungerechtigkeit ihrer Sklavenhalter erheben würden. ${ }^{39}$ Unübersehbar werden in dieser Passage die Aufrufe eines Diderot oder Raynal an einen künftigen Spartakus, aber auch die nur wenige Jahrzehnte und nur wenige hundert Kilometer entfernte Haitianische Revolution evoziert, die binnen weniger Jahre mit der verhassten Sklavenhaltergesellschaft ein für alle Mal Schluss machte. Die Avellaneda wusste nur zu genau, wie sehr der Schatten dieser erfolgreichen Revolution das Denken der kubanischen Anhänger einer forcierten Sklaven-Wirtschaft auf der Insel noch im gesamten 19. Jahrhundert verfolgte.

In Teresa hat Sab eine mitfühlende Seele für sich gewonnen. Denn ihre Sympathie und ihr Mitleid sind die Folgen seines Geständnisses: Sie vergießt eine Träne für Sab, wohingegen Carlota - wie die Leserschaft gegen Ende des Romans bemerken wird - die ihren erst nach dessen Ableben vergießen wird. Dieser hat seinerseits sehr wohl schon daran gedacht, sich $\mathrm{zu}$ bewaffnen und gegen die Unterdrücker zu erheben und den „terrible grito de libertad y venganza“40 ertönen zu lassen, also seinen schrecklichen Schrei der Vergeltung und Freiheit, und im Blut der Weißen zu baden. Der Zusammenbruch der profitablen Sklaverei-Wirtschaft ist allenthalben zu spüren, sollte auf Kuba aber noch ein weiteres halbes Jahrhundert auf sich warten lassen. Denn die nominelle Abschaffung der Sklaverei ging der letzten Beseitigung auf dem Kontinent im Jahre 1888 in Brasilien nur um wenige Jahre voraus.

Das Fazit des Romans der Avellaneda ist bitter: Der Traum einer gerechteren Welt ${ }^{41}$ bleibt ein Traum. Immer wieder erscheint Sab die Gestalt Carlotas hingegen als „aérea y pura“, als luftige Reinheit und Schönheit, die mit Bibelzitaten und Anspielungen reich garniert und bisweilen geradezu sakralisiert wird. ${ }^{42}$ Die

39 Ebda., S. 153.

40 Ebda., S. 157.

41 Ebda., S. 158.

42 Ebda. 
engelhafte Vision Carlotas verschwindet jedoch: Sab kehrt in die harte Realität als Mulatte und elender Sklave zurück, als „miserable esclavo“. ${ }^{43}$ Nichts vermag ihn, der zwischen allen Welten steht, in diesem Roman noch zu retten.

Denn Sabs Plan scheitert, Teresa dazu zu überreden, das sich in Sabs Hand befindliche und eigentlich Carlota gehörende Glückslos der Lotterie zu nehmen, dadurch reich zu werden und sich ausgerechnet mit Enrique zu vermählen, den sie wohl insgeheim zu lieben scheint. Sie weiß darum, dass allein Enrique der Existenz von Carlota Sinn verleiht. Nach langer, schmerzhafter Meditation bleibt Sab weit vom Haus entfernt besinnungslos liegen, wo ihn Sklaven am nächsten Morgen finden: Dies ist ein erstes Zeichen seines Körpers, der Belastung nicht mehr länger standhalten zu können. Ein Sklave berichtet später, Sab habe viel Blut aus dem Mund verloren - das Motiv des Blutsturzes also, das wir bereits in Esteban Echeverrías El Matadero kennengelernt hatten. Denn ein solcher Blutsturz verweist auf ein verletztes Herz, das zentrale Organ jeglichen romantischen Fühlens und Schreibens.

Doch auch an anderer Stelle ziehen Unheil verheißende Gewitterwolken auf: Enrique weiß um den nur noch geringen Besitzstand von Don Carlos, den Vater Carlotas, und sieht seine Hoffnungen zerstört, nicht nur eine reiche Mitgift, sondern auch die schöne Carlota heiraten zu können. Sein Vater hatte ihm bereits kühl mitgeteilt, er werde eine andere, reichere Kreolin für ihn suchen. ${ }^{44}$ Doch schon trifft Sab, vom Ingenio kommend, bei ihm ein und übergibt ihm einen Brief von Don Carlos, in welchem Carlotas Vater nicht nur vom baldigen Tod ihres Bruders und zugleich einzigen männlichen Erben berichtet, sondern auch in der Nachschrift ankündigt, Carlota habe den großen Lotteriepreis gewonnen und sei nun reicher als jemals zuvor: Diese Wendung ist ein Theatercoup, wie er der theaterversessenen Avellaneda gut zu Gesicht stehen musste.

Angesichts des wiedergewonnenen Reichtums Carlotas - der zweifellos dem Zufall, aber auch der überbringenden Hand Sabs zu verdanken ist - zeigt sich Enrique Otway dazu bereit, die reiche Kreolin sofort zu heiraten ${ }^{45}$ und jede andere Wahl seines umsichtigen Vaters auszuschlagen. Man könnte mit guten Gründen sagen, dass diese glückliche Fügung des Zufalls Carlota ins Verderben stürzen wird. Der vom Unglück verfolgte Sab, der einmal mehr den „postillon d'amour“ spielen musste und den entscheidenden Brief übergab, stöhnt angesichts der Vorstellung, dass Carlota schon in wenigen Stunden Enrique gehören werde: Enrique gehöre der Himmel, ihm selbst aber die Hölle. ${ }^{46}$ Sab bricht über dem Körper seines

43 Ebda., S. 161.

44 Ebda., S. 179.

45 Ebda., S. 187.

46 Ebda., S. $187 \mathrm{f}$. 
zu Tode gerittenen Pferdes zusammen, erneut strömt Blut aus seinem Mund. Er wird, am Herzen erkrankt, den Tod der romantischen Helden sterben - und dies als ein versklavter Mulatte, den Gertrudis Gómez de Avellaneda nicht nur mit Schönheit und Intelligenz, sondern bewusst mit jeglichen charakterlichen Vorzügen auszustatten beliebte. Sab ist in diesem abolitionistischen Roman charakterlich allen weißen Protagonisten weit überlegen.

Alles im Roman scheint sich nun dem Tode zuzuneigen: Der Bruder Carlotas, der Enkel der alten Martina, aber bald auch schon Sab werden sterben. Mit dem Todeskampf des kleinen Luis wird das Aussterben der indianischen Rasse ein letztes Mal im 19. Jahrhundert nachvollzogen. Auch Sabs Todesstunde rückt heran und er schreibt einen Abschieds-Brief, der alles ist, was von ihm bleibt. ${ }^{47}$ Denn die Schrift allein überdauert den Menschen und sein irdisches Leben. Sab verkörpert im Roman zweifellos die Rolle des sublimen Märtyrers der Liebe. ${ }^{48}$ Sein Brief wird bei Carlota später - zu spät! - die einstmals erhoffte Träne hervortreiben.

Der schöne Mulatte wird spätestens an dieser Stelle zum eigentlichen Titelhelden des Romans; seine Schrift ist im Grunde eine Herzensschrift, mit eigenem Blut, mit dem Herzen geschrieben, fast schon so, wie Juana Borrero - die Urgroßenkelin der Avellaneda - am Ende des romantischen Jahrhunderts in Kuba einen Brief nicht mit Tinte, sondern mit ihrem eigenen Blut schreiben wird. Während mehr als einer Stunde schreibt also der entkräftete Sab im Angesicht eines Porträts seiner Carlota seine letzten Worte nieder. Er stirbt kurze Zeit später in der Vorstellung, dass genau in seiner Todesstunde Enrique und Carlota sich ihr Jawort geben würden - eine Vorstellung, die im Übrigen zutreffend ist. ${ }^{49}$ So findet die Hochzeit Carlotas im Schatten gleich mehrerer just Verstorbener statt, wobei allerdings die Nachricht vom Tode Sabs die schöne Kreolin kaum zu berühren scheint. Diskret, aber dennoch erkennbar werden von der kubanischen Autorin einige negative Charaktermerkmale Carlotas in ihr literarisches Portrait eingefügt.

Spätestens jetzt ist auch für Teresa kein Platz mehr in der kolonialspanischen Gesellschaft Kubas - außer im Kloster. Selbst klimatisch passt alles zusammen: Erneut zieht ein schreckliches Gewitter auf, die Natur nimmt aktiv an der Handlung teil und erweist sich als Korrespondenznatur. Angesichts des Bildes der vor einem Kruzifix in ihrer engen Zelle knienden Teresa zeigt sich, dass auch sie einen sprechenden Namen besitzt, der auf Teresa de Jesús verweist, die Heilige Teresa von Avila. Zum gleichen Zeitpunkt sind die Jungvermählten glücklich und werden der kleine Luis und Sab begraben - Kontraste, die in ihrer literarischen

47 Ebda., S. 197.

48 Ebda., S. $197 \mathrm{f}$.

49 Ebda., S. 199. 
Herausarbeitung deutlich romantischen Zuschnitts sind. Gleichzeitig verweisen sie auf soziopolitischer Ebene auf das Scheitern ebenso der auf der Karibikinsel lange schon eroberten indigenen Bevölkerung wie der marginalisierten und ausgebeuteten Schwarzen und Mulatten. Sie bleiben als kulturelle Pole in diesem Gemälde ausgeblendet.

So ist es nun Zeit für die „Conclusión“ des Romans. ${ }^{50}$ Fünf Jahre sind seit dem Ende des letzten Kapitels vergangen, ein kunstvoller literarischer „blanc“ also, der dem Lesepublikum das weitere Schicksal der Romanfiguren ähnlich wie in Villaverdes Roman Cecilia Valdés abschließend vor Augen führt. Die Nonne, Sor Teresa, liegt im Sterben und will ein letztes Mal ihre Carlota sehen, die längst zur Señora de Otway geworden ist. Während die arme Teresa die „felicidad tranquila y solemne“, also das „ruhige und feierliche Glück“ erreicht hat, ist die reiche und von allen umschmeichelte Carlota unglücklich, da sie in einer merkantilen und an Spekulationen orientierten Atmosphäre lebt. ${ }^{51}$ Dies ist ein deutlicher Hinweis auf den Übergang von der Sklavenhaltergesellschaft alten Typs zu einer profitorientierten Kolonialwirtschaft eher britischen Zuschnitts, wo Carlotas „bellas ilusiones de su joven corazón“ schnell verwelkten: Illusions perdues also, um den Balzac'schen Romantitel zu bemühen. Es ist beeindruckend, in welchem Maße die junge kubanische Autorin bei ihrem ,kleinen Zeitvertreib، in der Lage war, die gesamtgesellschaftliche Totalität ihrer Insel darzustellen und Prognosen künftiger Entwicklung innerhalb eines breiten geoökonomischen und geokulturellen Zusammenhangs anzustellen - und dies alles literarisch in gelebtes Leben zu verwandeln.

Carlotas Leben hat sich grundsätzlich gewandelt: Don Carlos ist bereits verstorben, Enrique häufig auf Geschäftsreise in Havanna und den Vereinigten Staaten - alle Aktivitäten gehen geschäftig an ihr vorbei. Für sie ist letztlich alles zu Ende: Carlota hat ihren Mann, dessen Habgier und das Leben verstanden. Es ist explizit von „ilusiones perdidas“52 die Rede, jenen Verlorenen Illusionen, die Honoré de Balzac zwischen 1837 und 1843 in etwa zeitgleich in der französischen Literatur zu einem großen romantischen Thema machte. Gertrudis Gómez de Avellaneda war mit ihrem kleinen Roman Sab völlig auf der Höhe der Zeit.

Bei der sterbenden Teresa erhält Carlota Sabs letzten Brief, jenen Brief, den der junge Mulatte mit letzter Kraft in seiner Todesstunde niedergeschrieben hatte; ein Schreiben, das ein ganzes Leben und ein ganzer Tod sei. Teresa stirbt, und an ihrem klösterlichen Totenbett liest Carlota diesen Brief, in welchem der junge

50 Ebda., S. $210 \mathrm{ff}$.

51 Ebda., S. 213.

52 Ebda., S. 215. 
Mann seinen eigenen Tod minuziös beschreibt. Der Erzähler - wie immer in der ersten Person Plural - behauptet, den Brief selbst gesehen zu haben und ihn getreu im Gedächtnis zu bewahren: „la conservamos fielmente en la memoria. “53

In seinem dramatischen Abschiedsbrief stellt Sab grundlegende philosophische Überlegungen an und verweist darauf, dass er - obschon Sklave - doch stets das Schöne und Große geliebt habe. ${ }^{54}$ Er erweist sich auch in diesem seinem letzten Lebenszeichen als charakterlich allen anderen Romanfiguren überlegen, ist er doch ein Mensch, der nicht nur über hervorragende kognitive Fähigkeiten und eine hohe Intelligenz, sondern auch über Charakterstärke und vor allem ein liebendes, einfühlsames Herz verfügt. Als Mulatte ist er eine romantische Idealfigur, die sich stets in die anderen hineinzuversetzen versteht und für die ein möglichst unproblematisches Zusammenleben an oberster Stelle steht. Denn selbst angesichts seines ärgsten Widersachers um die Liebe Carlotas hat er stets ein faires Verhalten an den Tag gelegt: Sein ZusammenLebensWissen ${ }^{55}$ ist von nicht mehr irdischer Perfektion.

Noch ein letztes Mal erinnert er an die Lektüre von Liebesgeschichten, der sich Carlota und Sab während ihrer gemeinsamen Erziehung hingaben. Liebe und Lesen sind aufs Innigste miteinander verbunden. Denn wir lernen Liebe so, wie wir auch andere Kulturtechniken erlernen, und dies heißt für unseren Zusammenhang: Die beiden jungen Leute haben die Liebe durch Lesen gelernt. Wir haben es in diesem konkreten Falle mit dem Don-Quijote-Syndrom zu tun, das - wie bereits betont - Gustave Flaubert in Madame Bovary wenige Jahre später in Frankreich weiterentwickeln sollte. ${ }^{56}$

In der Konsequenz seiner gewiss romantischen Lektüren und Leseabenteuer begreift sich Sab als Märtyrer auf dem Altar der Liebe - wir könnten hinzufügen: auch auf dem Altar der Literatur und der Lektüre, deren spätes Opfer er wird. Doch noch in den letzten Minuten seines kurzen Lebens schreibt er eine Anrufung an den Engel der Lyrik, den „ángel de la poesía“ ${ }^{57}$ nieder, der schon bald seine Strahlen über dem Königreich der Intelligenz aufgehen lassen werde. Die große Dichterin der spanischen und kubanischen Dichtkunst huldigt in ihrem Roman der Poesie: Wer mag es ihr verdenken? Am Ende seines Todeskampfes und des Briefes aber taucht Sab ein in die Dunkelheit und das Schweigen. Die Feder fällt ihm aus der

53 Ebda., S. 218.

54 Ebda., S. 222.

55 Vgl. hierzu Ette, Ottmar: ZusammenLebensWissen. List, Last und Lust literarischer Konvivenz im globalen Maßstab (ÜberLebenswissen III). Berlin: Kulturverlag Kadmos 2010.

56 Vgl. Ette, Ottmar: Ottmar: LiebeLesen. S. 677-683.

57 Gómez de Avellaneda, Gertrudis: Sab, S. 228. 
Hand, was er ebenfalls noch niederschreibt, und seine Schlussworte sind: „Ich lebe bereits nicht mehr ... doch noch immer liebe ich. ${ }^{\text {"58 }}$ Die Liebe steht über allem!

Die schöne, aber vom Leben bitter enttäuschte Carlota - gesundheitlich stark angegriffen und von der rührigen Geschäftigkeit ihres Mannes entnervt - pilgert Nacht für Nacht, während ihres mehrmonatigen Aufenthalts in Cubitas, zum Grab von Sab und Luis. Danach verlieren sich ihre Spuren: Alle Nachforschungen der Erzählerfigur hätten keine Aufklärung ihres weiteren Schicksals gebracht. So könne man nur vermuten, dass sie nun im geschäftigen London und damit fernab ihres geographischen und kulturellen Ambientes leben dürfte. ${ }^{59}$ Damit wäre der Kreis des wirtschaftlichen und sozialen Aufstiegs der Otways geschlossen, die auf dem Umweg über Kuba zum Reichtum zuhause in England gelangten. Reich werde Carlota schon sein, so die Erzählerfigur; doch endet der Erzählerdiskurs im Roman mit einer letzten rhetorischen Frage: „Doch was auch immer ihr Schicksal und auf der Welt das Land, in dem sie nun lebt, sein könnten: Wird die Tochter der Tropen jemals den Sklaven vergessen können, der unter jenem schönen Himmel in einem bescheidenen Grabe ruht?“60

Gertrudis Gómez de Avellanedas Roman endet mit einer letzten Anrufung der Schönheit der Tropenwelt, und die Bezeichnung Carlotas als „Tochter der Tropen“ ist fraglos eine autobiographische Referenz der auf Kuba geborenen Dichterin. So sehr die Avellaneda aber auf ihre Geburt in den Tropen verweisen mag, stets wird doch auch in ihren Romanen diese Natur für die Augen einer spanischen beziehungsweise europäischen Leserschaft auto-exotisiert. Es geht damit um die Exotisierung des Eigenen im Zuge der Übernahme literarischer Muster europäischer Provenienz: Nicht umsonst hatten wir zu Beginn unserer Vorlesung schon auf Bernardin de Saint-Pierre und Chateaubriand verwiesen, die als intertextuelle Modelle einer europäischen Aneignung tropischer Landschaften dienen konnten. Selbst auf seiner Reise durch die amerikanischen Tropen hatte ein Alexander von Humboldt zusammen mit seinem französischen Forschungspartner Aimé Bonpland das Büchlein von Bernardin de Saint-Pierre aus dem Gepäck geholt und im Angesicht eines tropischen Unwetters die Wahrheit bestaunt, mit welcher in Paul et Virginie dieses Spektakel für europäische Leserinnen und Leser beschrieben wurde.

Die europäischen Vorbilder schaffen eine narrative Welt, in welcher das Andere als Anderes dargestellt wird, dann aber letztlich wieder zurücktritt, nicht

58 Ebda., S. 228: „ya no vivo ... pero aún amo.“

59 Ebda., S. 232.

60 Ebda., S. 231: „Pero cualquiera que sea su destino, y el país del mundo donde habite, ¿habrá podido olvidar la hija de los trópicos, al esclavo que descansa en una humilde sepultura bajo aquel hermoso cielo?“ 
ins Eigene integriert wird und $\mathrm{zu}$ einer bloßen Erinnerung, nicht aber zu einer lebensgestaltenden oder lebensverändernden Haltung gerinnt. Das Andere wird als Spektakel des Anderen genossen, nicht aber als ein Weiteres verstanden, sondern aus dem Eigenen als Anderes ausgegrenzt. ${ }^{61}$ Avellanedas Sab geht hier keineswegs über die europäischen Vorbilder hinaus - und dies im Übrigen auch nicht auf dem Gebiet des Abolitionismus, dem Verbot von 1844 zum Trotz, das Buch nach Kuba zu exportieren. 1835 war die spanische Übersetzung von Victor Hugos Bug-Jargal erschienen, ein Roman, den die kubanische Autorin zweifelsohne bei der Abfassung ihres Romantextes hinzuzog. Die Welt des Anderen trat für die kubanische und spanische Dichterin bald schon zurück in das Reich der anderen Welt.

Die spanischen wie die kreolischen Zeitgenossen freilich deuteten den Roman der Avellaneda als Verrat an ihrer Klasse und Herkunft, stellte sie doch nichts weniger dar als die Liebe eines Mulatten zu einer weißen Frau. Die umgekehrte Kombination - weiße Männer, die sich der Mulattinnen als Lustobjekte bedienten - war schon von den frühen Zeiten der Sklaverei an gang und gäbe geworden, doch barg die von der in Camagüey geborenen Autorin bevorzugte Umkehrung der Geschlechter und sozialen Hierarchien enormen gesellschaftlichen und biopolitischen Sprengstoff. In diesem Faktum ist wohl ein wesentlicher gesellschaftskritischer und geschlechterrollenkritischer Aspekt zu erblicken, der den Roman der Avellaneda so aufschlussreich macht.

Gleichzeitig darf man in dieser Tatsache aber auch einen wesentlichen Grund dafür erblicken, warum weder im Roman $S a b$, in dessen Personenkonstellation, noch in der Figur des schönen Mulatten eine nationale Allegorese breitenwirksam Raum greifen konnte. Denn in diesem Roman einer Frau wird, anders als in Cirilo Villaverdes Cecilia Valdés, der Sklave nicht allein zum Subjekt der Geschichte, er erwählt auch die weiße Frau als sein Liebesobjekt - ein Schlag ins Gesicht einer patriarchalischen Sklavenhaltergesellschaft. Zugleich handelt es sich um eine Konstellation, die wir unter gänzlich anderen Vorzeichen in Esteban Echeverrías La Cautiva kennengelernt hatten, wo freilich die Indianer bloß als wilde ungezügelte Masse erschienen.

Es fällt freilich schwer, in der Figur Carlotas ein Aufbegehren gegen angestammte Geschlechterrollen zu erkennen. Gewiss, Carlota leidet an ihrem Ausgeliefertsein und durchlebt eine von Melancholie geprägte physische Krankheit;

61 Vgl. zur dialektischen Beziehung zwischen dem Anderen und dem Weiteren Ette, Ottmar: Weiter denken. Viellogisches denken / viellogisches Denken und die Wege zu einer Epistemologie der Erweiterung. In: Romanistische Zeitschrift für Literaturgeschichte / Cahiers d'Histoire des Littératures Romanes (Heidelberg) XL, 1-4 (2016), S. 331-355. 
und sicherlich weist auch die Figur der im Verborgenen unglücklich liebenden Teresa nachdrücklich auf die Begrenztheit von Selbstverwirklichungsmöglichkeiten der Frauen im kolonialspanischen Kuba. Dies alles aber scheint mir nicht auszureichen, um hierin aus feministischer Perspektive neue genderspezifische Lebensentwürfe $\mathrm{zu}$ erkennen, die pragmatisch auch gesellschaftsverändernd wirken könnten. Doch wäre es ungerecht, einen solchen Anspruch an die 1860 in Havanna zur „poeta laureata“ gekrönten Dichterin zu erheben. Dass die in Kuba geborene Dichterin freilich eine die patriarchalische Gesellschaft kritisierende Position einnahm und für ihr eigenes Leben alternative Lebensentwürfe zu leben versuchte, bleibt unbestritten.

$S a b$ ist ein interessanter Versuch der Gegenläufigkeit zu Mustern, die wir in zeitgenössischen Romanen des 19. Jahrhunderts erkennen können. Im Scheitern der Liebe Sabs scheint bereits die mögliche Lebbarkeit von Lebensentwürfen auf, die sich jenseits des Rassismus dieses Jahrhunderts ansiedeln. Denn was imaginierbar und denkbar war, ist in diesem Prosatext schreibbar geworden; und vom Geschriebenen dieser imaginierten Heterosexualität in einem ethnische Grenzen überschreitenden Kontext ist es nur noch ein Schritt bis zur lebbaren und gelebten Lebenswirklichkeit. Die prospektive und zugleich politische oder soziale Veränderungen ankündigende Funktion der Literaturen der Welt wird in dieser fiktionalen Konstellation offenkundig.

Carlota dient nicht als nationale Allegorese; sie könnte es höchstens in negativer Form bezüglich des Ausgeliefertseins der Insel an den angelsächsischen Utilitarismus mit Blick auf die Zukunft sein. Doch auch Sab taugt nicht dazu: In einer patriarchalisch strukturierten Gesellschaft sind nationale Bilder nicht auf einen Mulatten, sondern höchstens - und auch dies anfangs nur eingeschränkt - auf eine schöne Mulattin zu projizieren. Die Repräsentation eines Staates oder einer Nation durch eine Frauengestalt ist tief in einer sich vom Abendland herleitenden Kultur verwurzelt - da hat ein Sklave nichts zu suchen.

Hinsichtlich einer nationalen Allegorese sowie mit Blick auf eine abolitionistische politische Stoßrichtung ist jedoch stets die Liebe das Gleitmittel literarischer Darstellung oder, wenn Sie so wollen, Motor der narrativen Dynamik wie der kreativen Aneignung durch die Leserschaft. Avellanedas Sab gelang es nicht was freilich auch nicht in der Absicht seiner Autorin lag -, die Figur des männlichen Protagonisten zur Figur einer nationalen (mulattischen) Fusion werden $\mathrm{zu}$ lassen. Es ist aufschlussreich, dieses ,Scheitern' mit dem Erfolg einer anderen männlichen Figur aus einem karibischen Roman zu vergleichen, die in der Tat nationenbildend wirkte beziehungsweise einen Entwurf nationaler Identität bei der Leserschaft erfolgreich projizierte.

Das Wort „projizierte“ ist hier sehr ernst gemeint, war diese Figur doch längst nicht mehr Teil einer Bevölkerungsgruppe, die wie die Mulatten eine ernsthafte 
Konkurrenz für die kreolische Oberschicht im Kampf um die politische Macht darstellte. Die Titelfigur von Manuel de Jesús Galváns dominikanischem Erfolgsroman Enriquillo ist gerade kein Mulatte oder Schwarzer, sondern Angehöriger einer Ethnie, welche innerhalb der dominikanischen Geschichte beziehungsweise der Geschichte der Insel Hispaniola zum damaligen Zeitpunkt seit dreihundert Jahren keinerlei konkrete Bedrohung mehr darstellte und deren Reste längst verloren gegangen waren. Denn dieser Enriquillo, nationale Identitätsfigur der Dominikanischen Republik, nach der bis heute ein großer Binnensee benannt ist, welcher der Schauplatz einiger im Roman dargestellter Handlungen war, ist weder Schwarzer noch Weißer noch Mulatte: Er ist Indianer und damit so etwas wie der kleine Luis, der in Avellanedas Roman den Untergang der indigenen Bevölkerung symbolisiert.

Gestatten Sie mir noch einige abschließende Bemerkungen zu Gertrudis Gómez de Avellaneda! Denn es steht außer Frage, dass die zu Unrecht von einem breiteren Publikum vergessene Dichterin gerade im Kontext eines neuen Interesses an Schriftstellerinnen und der Problematik von Geschlechterbeziehungen wieder mehr ins Rampenlicht treten wird. ${ }^{62} \mathrm{Zu}$ diesem Ziel möchte auch der vorliegende Band der Vorlesungen beitragen. Vor allem ist es uns darum zu tun, den Blick stärker auf die hochverdichtete und eher in den Hintergrund gerückte Prosa von Gertrudis zu lenken. Denn diese verdient es, im Kontext jener Autorinnen und Autoren gelesen zu werden, welche die Sattelzeit der Romantik interessanterweise nicht von einem postkolonialen, sondern von einem noch kolonialen Standort aus zu repräsentieren wussten. Gertrudis Gómez de Avellaneda gehört zweifellos zu den wichtigsten Autor`innen, welche das 19. Jahrhundert zu bieten hat. Sie ist ganz gewiss das weibliche Gesicht der spanischen wie der kubanischen Lyrik der Romantik.

Die Avellaneda repräsentiert durch ihr Leben wie durch ihr Schreiben daher wie keine andere Autorin eine Romantik, die sich zwischen zwei Welten ansiedelt und den Logiken beider Seiten des Atlantik gehorcht. Denn sie gestaltete diesen transatlantischen Spielraum ebenso innerhalb des literarischen Feldes in Spanien, wo sie vielfach ausgezeichnet wurde, wie in Kuba, wo sie zur Dichterin gekrönt wurde. Diese schlichte Tatsache scheint mir für die literaturwissenschaftliche Forschung von großer Relevanz zu sein. Avellaneda besetzte folglich

62 Vgl. hierzu u. a. Rodríguez Gutiérrez, Milena (Hg.): Otra Cuba secreta. Antología de poetas cubanas del XIX y del XX. De Gertrudis Gómez de Avellaneda a Reina María Rodríguez. Con una breve muestra de poetas posteriores. Madrid: Editorial Verbum 2011; sowie dies.: Entre el cacharro doméstico y la „vía láctea“. Poetas cubanas e hispanoamericanas. Sevilla: Ilmuniaciones Renacimiento 2012. 
Positionen zugleich innerhalb des kubanischen wie des spanischen literarischen Feldes, wurde in Madrid wie in Havanna zu Lebzeiten als eine der großen Vertreterinnen der Romantik verehrt und vermochte es, ein eigenständiges Leben als Frau zu führen. Ihr kam zweifellos eine gewisse Vorreiterstellung bezüglich der Infragestellung von Geschlechterpositionen zu, wobei sie auch interethnische Relationen in ihr literarisches Spiel miteinbezog.

Die Schriftstellerin war darüber hinaus in den verschiedensten Gattungen zu Hause: Sie schrieb Romane, triumphierte mit ihren Stücken auf den madrilenischen Bühnen und bestach durch ihre stets autobiographisch eingefärbte Lyrik, in welcher sie vorzugsweise ihre eigenen Liebesdramen literarisch fruchtbar werden ließ. Anlässe hierfür gab es genug, war die Avellaneda doch nicht nur durch den frühen Tod ihres Vaters und die überstürzte Hochzeit ihrer Mutter, sondern auch durch den Tod zweier Ehemänner und ihre unglückliche Liebe zu einem zweitklassigen spanischen Autor gezeichnet. Doch ihr Durchhaltevermögen gerade als Frau war bewundernswert!

Und noch ein letzter Hinweis, um ihr literarisches Bild abzurunden: Ganz in romantischer Tradition ist ihr Interesse an traditionellen Stoffen und Gegenständen der Volkskultur zu verstehen, wie ihre Tradiciones zeigen, welche ebenso kubanische und hispanoamerikanische wie iberische, vorzugsweise pyrenäische und baskische Geschichten und Legenden bearbeiten und neu erzählen. So wurde sie auch zur großen Vermittlerin kubanischer Sitten und Traditionen nach Spanien und spanischer Lebensbilder nach Kuba; eine Vermittlungsfunktion, die auch mit Blick auf den in der Romantik so wichtigen volkskulturellen Pol von großer Bedeutung für ihre Stellung innerhalb eines romantischen Schreibens zwischen zwei Welten war.

Vergessen wir nicht: Die in Kuba geborene Gertrudis Gómez de Avellaneda hatte bereits in Sab eine unverkennbar kritische, ja feindliche Haltung gegenüber der spanischen Eroberung Amerikas vorgetragen, vergoss doch nicht umsonst die schöne Carlota heiße, wenn auch nicht zahllose Tränen angesichts der vielen Gräueltaten iberischer Konquistadoren! Die alte Martina - zusammen mit dem kleinen todgeweihten Luis die letzte Vertreterin der indigenen Bevölkerung auf der Insel - hatte die indianische Thematik in das Romanschaffen der Avellaneda eingeführt. Die durchaus rebellische kubanische Autorin blendete damit eine Kontinuität von Rebellionen ein, welche nach dem Auslöschen der indigenen Bevölkerung auf Kuba und ihrer weitgehenden Vernichtung in der karibischen Inselwelt von den schwarzen Sklaven, sozusagen den importierten Eingeborenen, fortgeführt wurde.

Was lag nun näher, als dass sich Gertrudis Gómez de Avellaneda der Frage der indigenen Bevölkerung und den damit verbundenen kulturellen Herausforderungen nicht mehr im Kontext des neunzehnten, sondern vielmehr des sechzehnten 
Jahrhunderts annäherte? Sie verband damit die Traditionslinie der Novela sentimental à la Walter Scott mit jener des historischen Romans, der sich ebenfalls auf Scott berufen konnte. Wir erkennen, dass diese beiden (wenn auch beileibe nicht einzigen) Traditionslinien des romantischen Romans auf engere Weise miteinander verbunden sind, als es die klassifizierenden Scheidungen bisweilen nahezulegen scheinen.

In der literarischen Orchestrierung ihres erstmals 1846, also kaum 5 Jahre nach $S a b$ veröffentlichten Romans Guatimozín erkennen wir von Anfang an jenen Grundzug des romantischen Romans lateinamerikanischer Prägung, die Problematik der nationalen und ethnischen Frage mit der Liebesgeschichte und der Suche nach den Rändern der Gesellschaft zu verbinden. Diese waren als Marginalisierte in der vorgängigen, vom Neoclasicismo geprägten Tradition nicht existent gewesen. An dieser Stelle tritt folglich zumindest potenziell ein weiterer kultureller Pol in den Horizont des Romanschaffens lateinamerikanischer Autor^innen.

Wieder wählt die Kubanerin einen männlichen Titelhelden; und wieder stellt sie diesem als Opponenten einen weißen Mann europäischer Herkunft entgegen, nur dass in diesem Falle das Personal des Romans - sagen wir es vorsichtig weniger fiktionaler als historischer Provenienz ist. Die „entrada en materia“ des Romans macht die gewählte und hier nur kurz zu skizzierende Grundkonstellation deutlich:

\begin{abstract}
Mehr oder minder drei Jahre waren seit jenem denkwürdigen Tage vergangen, an welchem sich der besiegte und gefangengenommene junge und heldenhafte Kaiser Guatimozín nach dreiundneunzig Tagen harter Belagerung den spanischen Waffen unterworfen und die schöne Hauptstadt des mexikanischen Reiches übergeben hatte. Drei Jahre waren es schon seit jenem großen Ereignis, dessen unermessliche Resonanz noch immer Europa zutiefst bewegte, und es war dem siegreichen Caudillo trotz seines Genies und trotz seines Glückes noch nicht möglich gewesen, alle Provinzen des sich so weit ausdehnenden Neuspanien, das er mit seinem Stahle für die altehrwürdige Krone Kastiliens erobert hatte, vollständig zu unterwerfen, doch hatte jene Zeit mehr als genügt, um mit innigen Opfern seines Herzens und schamvollen Vergehen seiner eigenen Leute die trunken machende Süße seines Ruhmes zu verbittern. ${ }^{63}$
\end{abstract}

Es ist an dieser Stelle unserer Vorlesung nicht möglich, nach Sab einen zweiten Roman der zu Unrecht lange Zeit als Romanschriftstellerin vergessenen Autorin vorzustellen. Und doch wird in dieser kurzen Gegenüberstellung beider Helden innerhalb eines verblüffend knappen Zeitraums anschaulich, wie rasch die Distanz zwischen der ,großen' Geschichte - der Eroberung Mexikos und der

63 Gómez de Avellaneda, Gertrudis: Guatimozín In Dies.: Obras de doña Gertrudis de Avellaneda. Bd. 5. Madrid: Ediciones Atlas 1981, S. 207. 
Unterwerfung des letzten Aztekenherrschers Cuauhtémoc - und der ,kleinen', individuellen Geschichte, ja dem romantischen Seelendrama der beteiligten historischen Gestalten durchschritten wird. Wenn freilich bisweilen behauptet werden konnte, die Avellaneda sei mit ihrem Roman von 1846 dem Indigenismus zuzurechnen, so kann einer derartigen Position an dieser Stelle leider nicht beigepflichtet werden.

Sicherlich ist in derartigen Stellungnahmen die Einsicht enthalten, dass Gertrudis Gómez de Avellaneda in gewisser Weise feministische wie indigenistische Positionen vorwegnahm. Das diegetische Setting des Romans wie auch die ästhetisch-ideologische Position seiner Schöpferin lässt keinen Zweifel daran, dass es der Romantikerin im Gegensatz zu den Vertretern des Indigenismus Ende des neunzehnten und vor allem in den ersten Jahrzehnten des zwanzigsten Jahrhunderts keineswegs darauf ankam, die existenzielle Problematik der zu ihrer Zeit lebenden Indianer aufzuwerfen. Auch die kulturellen Dimensionen indigener Völker wurden von ihr weder auf- noch nachgezeichnet. Vergessen wir dabei nicht, dass es selbst im „Oriente“ Kubas zum damaligen Zeitpunkt keine indigene Bevölkerung mehr gab, wobei freilich in Mexiko oder Mittelamerika, im andinen Raum oder in Brasilien unterschiedlichste indigene Völker die Kultur der jeweiligen Staaten oder Gebiete zum Teil entscheidend mitprägten!

Es ging Gertrudis Gómez de Avellaneda nicht um die Lebensumstände ihrer damaligen indianischen Zeitgenossen, sondern um die längst zur Historie, ja zur Legende gewordenen, für die aktuelle Gegenwart aber ungefährlichen Indianer, wie sie sich ihr durch eine Reihe berühmter Intertexte erschloss. Ihre Position ist damit dem Indianismus, keineswegs aber dem Indigenismus zuzuordnen. Wer dies übersieht, begreift nicht, dass sich nicht alles als indigenistisch bezeichnen lässt, was Partei für die indigene Bevölkerung ergreift und mit einer starken Idealisierung insbesondere historische Themen aufgreift.

Die Forschungsliteratur hat zur Genüge aufgezeigt, wie viel unsere Tula auch in diesem Roman den literarischen, das Bild der Indigenen romantisierenden Texten Chateaubriands zum historischen Hintergrund, aber vor allem den Schriften des Hernán Cortés, dem sprachgewaltigen Eroberer selbst, sowie Bernal Díaz del Castillo verdankte. Letzterer war Cortés' spanischer Mitstreiter mit der Perspektive eines einfachen Soldaten, welcher Tulas Text ebenso prägte wie Antonio de Solís oder Herrera, wichtige spanische Chronisten und Geschichtsschreiber, sowie Francisco Clavijero und William Robertson, philosophische Vertreter des neuspanischen und schottischen 18. Jahrhunderts. In Rückgriff auf diese Bezugstexte gelang es Gertrudis Gómez de Avellaneda, ein bewegtes und buntes Bild der spanischen Eroberung des Aztekenreiches zu entfalten, das die Zeitgenossen ansprach, auf phantasievolle Weise Szenen der Conquista rekonstruierte und für romantische Leserschichten erschloss. 
Die aktuellen Indigenen freilich sind von diesen literarischen Kreationen nicht betroffen: Die Avellaneda widmete sich dem Indianer, nicht den Indianern, sie vertrat eine exotisierende und aus europäischer Sicht historizistische Position, in welcher es nicht an Kritik an den Gräueltaten mangelte, Massaker freilich, die längst Vergangenheit oder - wie man vielleicht besser noch sagen könnte - zu Text geworden waren. In ihrem Roman Guatimozín werden nicht indigenistische, wohl aber jene indianistischen Positionen und Modellierungen nationaler Identität angelegt und gewiss auch vorweggenommen, die über 40 Jahre später dem dominikanischen Autor Manuel de Jesús Galván einen großen Erfolg bescheren sollten.

Wir werden uns zu gegebenem Zeitpunkt diesem Werk aus derselben kulturellen Area der Karibik widmen. Gertrudis Gómez de Avellaneda, die Autorin von Sab und Guatimozin, ist ihrerseits jedoch das prägende Gesicht eines 19. Jahrhunderts, das für ein Schreiben zwischen den beiden Welten, aber auch zwischen kolonialer Stagnation und postkolonialem Aufbruch stand - in einer Zeit, in der sich das transatlantische Verhältnis zwischen Europa und den Amerikas signifikant zu verändern begann. Es gibt kaum ein anderes literarisches Werk, das diese Veränderungen im Verhältnis zwischen beiden Welten auf eindrucksvollere Weise reflektiert als das der kubanisch-spanischen Schriftstellerin. 